Published in final edited form as:

J Org Chem. 2021 October 01; 86(19): 13535-13547. doi:10.1021/acs.joc.1c01442.

\title{
Folding in Place: Design of $\beta$-Strap Motifs to Stabilize the Folding of Hairpins with Long Loops
}

\author{
Alexis D. Richaud, Guangkuan Zhao, Samir Hobloss, Stéphane P. Roche \\ Department of Chemistry and Biochemistry, Florida Atlantic University Boca Raton, Florida \\ 33431, United States
}

\begin{abstract}
Despite their pivotal role in defining antibody affinity and protein function, $\beta$-hairpins harboring long noncanonical loops remain synthetically challenging because of the large entropic penalty associated with their conformational folding. Little is known about the contribution and impact of stabilizing motifs on the folding of $\beta$-hairpins with loops of variable length and plasticity. Here, we report a design of minimalist $\beta$-straps (strap $=$ strand + cap) that offset the entropic cost of long-loop folding. The judicious positioning of noncovalent interactions (hydrophobic cluster and salt-bridge) within the novel 8-mer $\beta$-strap design $\mathrm{RW}(\mathrm{V} / \mathrm{H}) \mathrm{W} \cdots \mathrm{WVWE}$ stabilizes hairpins with up to 10 -residue loops of varying degrees of plasticity ( $T_{\mathrm{m}}$ up to $52{ }^{\circ} \mathrm{C} ; 88 \pm 1 \%$ folded at $18{ }^{\circ} \mathrm{C}$ ). This "hyper" thermostable $\beta$-strap outperforms the previous gold-standard technology of $\beta$-strand- $\beta$-cap (16-mer) and provides a foundation for producing new classes of long hairpins as a viable and practical alternative to macrocyclic peptides.
\end{abstract}

\section{Graphical Abstract}

\footnotetext{
Corresponding Author Stéphane P. Roche - Department of Chemistry and Biochemistry, Florida Atlantic University, Boca Raton, Florida 33431, United States; sroche2@fau.edu.

Author Contributions

This project was conceived by S.P.R. A.D.R., S.H., and G.Z. performed the research experiments and S.P.R. with A.D.R. analyzed the data. The manuscript was written through contributions of S.P.R. and A.D.R. All authors have given approval to the final version of the manuscript.

Supporting Information

The Supporting Information is available free of charge at https://pubs.acs.org/doi/10.1021/acs.joc.1c01442.

Raw CD data as well as a detailed protocol for the best-fit routine (two-state model) and the resulting Gibbs-Helmholtz equation obtained for each peptide 1-3 (XLSX)

Tables of NMR chemical shifts, structural assignments data including ${ }^{1} \mathrm{H}$, TOCSY, NOESY, magnified TOCSY/NOESY overlays, and HSQC spectra, as well as CD and VT-CD spectra, and HPLC chromatograms to determine structure and purity for each peptide 1-3 and the corresponding random coils SI-RC1-4 (PDF)

The authors declare no competing financial interest.
} 


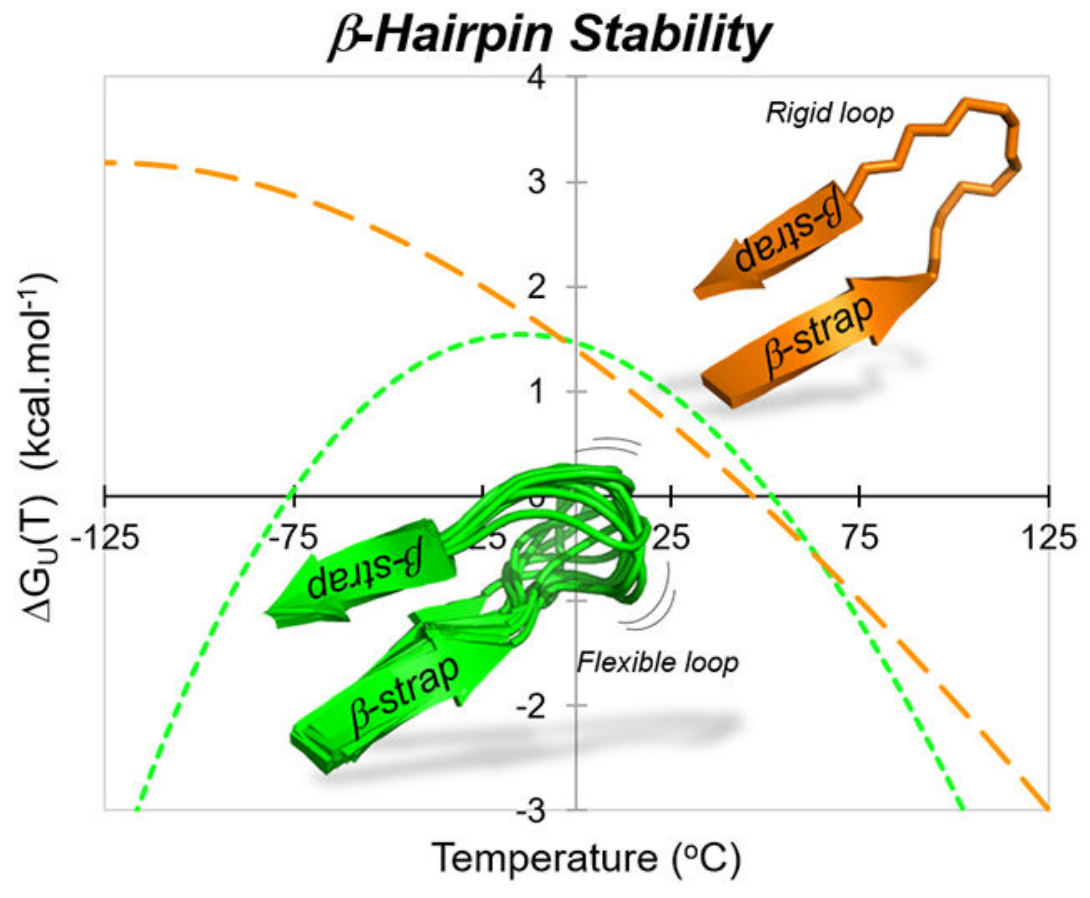

\section{INTRODUCTION}

In the past 2 decades, the mimicry of proteins' secondary structures into peptide foldamers has emerged as a powerful modality to build novel materials ${ }^{1}$ and bioactive macromolecules. ${ }^{2}$ The identification of stand-alone foldamers such as $\beta$-hairpins and their development into macrocyclic mimics have proved to be a prolific strategy for the development of protein-protein interaction (PPI) inhibitors. ${ }^{3}$ Although pivotal advances in the mimicry of helices, turns, and $\beta$-sheets have been made, ${ }^{4}$ the general design principles guiding the folding of $\beta$-hairpins with long loops are still in their infancy. ${ }^{5}$ In fact, the folding of $\beta$-hairpin peptides is essentially limited to short turn-induced $\beta$-sheets, in which the turn-locus forces the secondary structure nucleation through chain reversal and the formation of an antiparallel strand register. ${ }^{3,6}$ In stark contrast, most $\beta$-hairpins typically found in the proteome are "turnless" with long and unstructured loops ( $\beta$-arches) stabilized by $\beta$-pleated sheets within secondary and tertiary structures. ${ }^{7}$ It is proposed that the folding of these turnless long $\beta$-hairpins arises not only from loop nucleation ${ }^{8}$ but also from pairing-residue interactions ${ }^{9}$ and hydrophobic clusters formation ${ }^{10}$ along $\beta$-sheets. ${ }^{11}$ From a fundamental standpoint, the current frontier in hairpin structures mimicking closely the native folds found in protein remains largely limited to short [2:2]/[2:4]-, [3:5]-, [4:4]/ [4:6] hairpins. ${ }^{12,13}$ These synthetic hairpins are typically nucleated around a 4-residue loop having an innate turn propensity (e.g., DDATKT and NPATGK sequences, Figure 1A). ${ }^{8 c, 14}$

Different challenges are indeed associated with length: short loops in [2:2]/[2:4]- and [3:5]-hairpins are usually centered around specific $\beta$-turns and $\beta$-bulges, ${ }^{15}$ while the foldings of [4:4]/[4:6]- and larger hairpins are exceedingly more difficult to control due to the conformational space accessible by random sequences of $a$-amino acids and the innate conformational strain held by their structures. Except for some rare examples of 
long hairpins ( $\geq 10$-mer loop) championed by Andersen ${ }^{16}$ by developing a $\beta$-cap- $\beta$-strand stabilizing motif of 16 amino acids length, the significant entropic penalty inherent to the nucleation of long loops and their vulnerability to fraying have basically hindered their synthetic development. For these reasons, most structural studies have only evaluated the formation of long loops built from simpler and highly flexible polyglycine chains. ${ }^{16,17}$ Other studies have shown that associating $\beta$-strands and $\beta$-caps of $10-12$ residues is the minimal length required to stabilize hairpins with relatively short loops ( $2-4$ residues) ${ }^{18} \mathrm{~A}$ net improvement of design is needed to create long and well-folded $\beta$-hairpins at physiological temperatures and obtain a viable and practical synthetic alternative to macrocyclic peptides of a large size (>10-mer). ${ }^{19}$

Despite the need for novel protein and antibody loop mimics, the lack of technology has hampered the synthesis of large hairpin modalities suitable to this space. Therefore, we were drawn to revisit this issue by designing some minimalist $\beta$-straps amenable to crafting loops of conceptually any length, sequence, and conformational strain (Figure 2). ${ }^{20}$ To this aim, we targeted the synthesis of a [10:12]-hairpin, which mimics a highly constrained loop (RDYRFDMGFD sequence) excised from the heavy chain complementary determining region 3 (CDR-H3) of the marketed antibody drug pembrolizumab, a programmed cell-death 1 inhibitor (Figure 1B). ${ }^{21}$

We hypothesized that combining several types of noncovalent interactions ${ }^{22}$ at nonhydrogen-bonded (NHB) and hydrogen-bonded (HB) sites would enable long constructs of typical $\beta$-cap-strand-loop-strand- $\beta$-cap architecture to be truncated into their simplest forms $\beta$-strap-loop- $\beta$-strap and still retain a high efficacy (Figure 2 ). Here, we report a sideby-side comparison between three strap designs 1-3, which demonstrates that a judicious combination of Coulombic interactions at the hairpin termini HB-site (persisting at longer distances) with van der Walls and hydrophobic contacts at NHB-sites can overcome the loop entropy to strengthen hairpin structures (Table 1).

\section{RESULTS AND DISCUSSION}

We set our aim as to construct monomeric $\beta$-hairpins soluble in water and stable at physiological temperatures. To understand the structural requirements of stabilizing motifs in the straps, we began by designing peptide constructs by including the DDATKT ${ }^{14 \mathrm{a}}$ and NPATGK, ${ }^{8 \mathrm{c}} d$ loops of known [4:6] hairpins as reversing turn loci inspired from GB1, and the B1 domain of Streptococcal protein G (Table 1). ${ }^{23}$ The underlying idea was to compare peptides 1a-c harboring an Ac-W $\cdots$ WTG- $\mathrm{NH}_{2} \beta$-strap, inspired by a capping created by Andersen (Table 1, entries 6-8) ${ }^{15,24}$ with constructs 2a-b having an Ac-WVW $\cdots \mathrm{WVW}-\mathrm{NH}_{2}$ $\beta$-strap (Table 1, entries 9 and 10) truncated mimic of the tryptophan zipper motif (Trpzip) developed by Cochran ${ }^{25}$ such as the Trpzip9, and some of most stable stand-alone hairpins known to date HP7 and GB1m3 $\left(60 \leq T_{\mathrm{m}} \leq 92{ }^{\circ} \mathrm{C}\right.$, entries $\left.3-5\right) \cdot{ }^{26,27}$ Second, we evaluated the stability of a novel RW(V/HW) $\cdots(\mathrm{WV}) \mathrm{WE} \beta$-strap, which combined an ionic pair at the HB-site termini in addition to the Trpzip hydrophobic core of constructs 3a-c (entries 11 13) in comparison to the Coulombic capping of $\beta$-hairpin HP7 previously positioned at an NHB-site (entry 3 ). Here, we demonstrated the superiority of $\beta$-strap $\mathbf{3}$ and further evaluated its ability to structure longer loops (e.g., hairpins 3d-f, entries 14-16). All peptides 1-3 were 
synthesized on resins using a typical Fmoc-based solid-phase peptide synthesis (SPPS) in $15-70 \%$ yields with relatively high crude purity after cleavage ( $278 \%$ by RP-HPLC), which was improved by semipreparative RP-HPLC purification when needed.

The final deprotection/cleavage step proved to be challenging for constructs $\mathbf{2}$ due to the steric hindrance imparted by the resin on the nearby $\mathrm{C}$-terminal Trp residue leading to side reactions and irreversible reattachment of the peptide to the resin. ${ }^{28}$

\section{Secondary Structures and Thermal Stability Analysis Determined by Circular Dichroism (CD) Spectroscopy.}

Changes in molar ellipticity intensity as a function of temperature $[\theta(\mathrm{T})]$ can be exploited at specific wavelengths of $\mathrm{CD}$ spectra to examine the thermodynamic folding/unfolding transition of secondary structures. ${ }^{29}$ For example, the cross-strand interaction between W/W pairs positioned at NHB-sites is well known to produce a distinct and intense exciton couplet at 212 and $228 \pm 1 \mathrm{~nm}$ (negative/positive maxima) from a $\pi-\pi^{*}$ transition, which can be used as a local spectroscopic probe of $\beta$-hairpin folding. ${ }^{30,31}$ Indeed, the edge-to-face (EtF) geometry between indole rings of facing Trp residues ${ }^{30,32}$ responsible for the $\pi-\pi^{*}$ transition is also coupled with a significant electrostatic stabilization created by multiple $\mathrm{CH}-\pi$ interactions. ${ }^{33}$ As a result, the W/W EtF interaction was widely exploited to measure the level of backbone folding in hairpins. ${ }^{30 \mathrm{~b}}$ The decrease in amplitude of the prototypical $228 \mathrm{~nm}$ exciton intensity upon heating was therefore monitored by $\mathrm{CD}$ spectroscopy to evaluate the thermal denaturation of $\beta$-straps 1-3 and determine the thermodynamic parameters characterizing the transition between the folded and unfolded states of hairpins (Figure 3).

To analyze these secondary structures in solution, several synthetic "random coils" SI-RC1$\mathbf{4}$ arguably similar to the corresponding $\beta$-strap 1-3 in length, primary sequence, and compactness were synthesized and fully characterized by variable-temperature circular dichroism (VT-CD) spectra and NMR experiments. ${ }^{14 d, 34}$ The unfolded nature of these constructs SI-RC1-4 was confirmed (see linear behavior, Figure 3A) and exploited to calibrate both CD unfolded baselines and NMR chemical shift deviations (CSDs). ${ }^{25 b, 26}$ The far-UV CD spectra of peptides 1-3 were recorded in phosphate buffer (with up to $20 \%$ $\mathrm{MeOH}$ added in rare cases, see the Experimental Section, Table 2) upon a gradual increase of temperature $\left(0-95^{\circ} \mathrm{C}\right)$. The reversibility of the thermal denaturations was ascertained by obtaining a quasi-identical recovery of spectral features for all constructs 1-3 upon cooling the temperature back to $0{ }^{\circ} \mathrm{C}$. It is well known that the molar ellipticity intensities of the 228 $\mathrm{nm}$ exciton vary considerably even for fully folded hairpins $\left([\theta]_{228}+290000\right.$ to $\left.+560000^{\circ}\right)$ due to minor differences in perpendicularity between indole rings, ${ }^{30 b, 31}$ thus raw melting curves from $[\theta(\mathrm{T})]_{228}$ could not be utilized to determine fractions of folding precisely. Instead, raw data were corrected by subtracting the corresponding random coil ellipticity values obtained at $95{ }^{\circ} \mathrm{C}[\theta]_{\mathrm{RC}(95)}$ (unfolded baseline SI-RC1-4) and normalized (per Trp pair) for direct comparison. ${ }^{35}$ The corrected and normalized raw ellipticity intensities $[\theta]_{228}$ for hairpins 1-3 were then fitted to a theoretical $[\theta(T)]_{228}$ melt curve as a function of temperature (eq S1) using the thermodynamic Gibbs-Helmholtz equation describing a twostate model (folded/unfolded states). ${ }^{29}$ The best-fitted melting curves of unfolding transition 
were computed for hairpins 1-3 by allowing $\Delta H_{\mathrm{m}}, T_{\mathrm{m}}$, and $\Delta C_{\mathrm{pF}}{ }^{\circ}$ to freely vary using a nonlinear least square fitting routine, ${ }^{29}$ while using the approximation that the heat capacity is constant over the range of temperature evaluated: $\Delta C_{\mathrm{pF}}{ }^{\circ}<0$ (Figure S2). ${ }^{34,36}$ Plots of $\%$-folding $\left(\chi_{\mathrm{F}}\right)$ for each hairpin 1-3 as a function of temperature were obtained (Figure $3 \mathrm{~A}$ ), along with the thermal stability curves (Figure 3B), melting temperatures $\left(T_{\mathrm{m}}\right),{ }^{37}$ and thermodynamic parameters characterizing the unfolding transitions (Figure 3C). As shown by the goodness of the fit determined on $[\theta(\mathrm{T})]_{228}$ (avg. $R^{2}$ of 0.98 and RMSD of 5,179 $\mathrm{deg} \cdot \mathrm{cm}^{2} \cdot \mathrm{dmol}^{-1}$ ), these melting curves indicated a temperature-induced unfolding typical from a hairpin/coil transition in agreement with a two-state model via a single transition barrier resulting from the cooperativity of fracture between the strap and loop segments. Even though the midpoint inflection of the melt curvature (at $T_{\mathrm{m}}$ ) cannot be consistently observed due to the finite window of experimental temperatures (Figure 3A), both the cooperativity of the transitions and isodichroic points can be estimated from the extrapolated melts and the raw CD stacks presented in the Supporting Information. In addition to the thermal denaturation, the two-state model approximation was further validated by isothermal urea-induced denaturation titrations (0-15 M) on hairpins $\mathbf{2 a}$ and 3b-d (Figure S18). ${ }^{34}$

CD melts for hairpins 1a-c, built around an Ac-W $\cdots$ WTG- $\mathrm{NH}_{2} \beta$-strap motif, provided thermodynamic parameters representative of a relatively poor folding $\left(\Delta G_{\mathrm{F}}{ }^{\circ} \sim 0\right)$. In contrast to the initial report by Andersen, ${ }^{16 a}$ our results suggest that this strap is not extremely stabilizing for longer loops. Even so, the innate nucleation induced by the DDATKT and NPATGK loops was shown to affect the overall hairpin structures (1a vs $\mathbf{1 b}, \Delta \Delta G_{\mathrm{F}}{ }^{\circ}=-0.51$ $\mathrm{kcal} / \mathrm{mol}$ ), suggesting that a DDATKT sequence might be a more favorable loop. Adding a pair of aromatic residues $\mathrm{F}(\mathrm{S} \pm 2)$ to the $\beta$-strap flanking the loop in 1c resulted in the most stable hairpin of this series despite a modest folding $\chi_{\mathrm{F}}(291)$ of $63 \pm 4 \%$ (Table 1, entry 8). In contrast, hairpin $2 \mathbf{a}$ stabilized by the Ac-WVW $\cdots$ WVW-NH 2 strap and derived from a truncated Trpzip9 (Table 1, entry 5 vs entry 9) revealed some remarkable folding properties $\left(T_{\mathrm{m}}(\mathbf{2 a})>100{ }^{\circ} \mathrm{C} ; \Delta G_{\mathrm{F}}{ }^{\circ}=-2.36 \mathrm{kcal} / \mathrm{mol}\right)$. This strap was further evaluated by crafting a more flexible GPGTGK loop sequence in hairpin $\mathbf{2 b}$. Surprisingly, the N4G and A6G substitutions largely abrogated the fold of hairpin $2 \mathbf{b}$ (Figure 3B). The important entropic penalty associated with this flexible loop $\left(\mathrm{T} \cdot \Delta \Delta S_{\mathrm{F}}{ }^{\circ}(\mathbf{2 b} / \mathbf{2 a})=+3.25 \mathrm{kcal} / \mathrm{mol}\right)$ could not be compensated by the noncovalent interactions within the strap. Another drawback of this short $\beta$-strap is its high hydrophobicity in comparison to the longer original Trpzip sequence, ${ }^{25 \mathrm{~d}}$ thus creating peptides poorly soluble in both water and organic solvents (e.g., $\mathrm{MeOH}$, TFE, or DMSO).

To counterbalance this hydrophobic effect, improve aqueous solubility, and increase amphipathicity, an ionic pair was inserted at the terminal HB-site resulting in the RW(V/HW) $\cdots(\mathrm{WV}) \mathrm{WE}$ strap design 3. Hairpins 3a-c demonstrated some of the most interesting thermodynamic properties with high melting temperatures $\left(62 \leq T_{\mathrm{m}} \leq 98^{\circ} \mathrm{C}\right)$ and sizable stability $\left(-1.63 \leq \Delta G_{\mathrm{F}}{ }^{\circ} \leq-0.87 \mathrm{kcal} / \mathrm{mol}\right)$. As shown in Figure $3 \mathrm{~A}$, melt curves of hairpins $\mathbf{3 a}$ vs $\mathbf{3} \mathbf{b}$ highlighted some subtle differences in stability. Given the large heat capacity $\Delta C_{\mathrm{pF}}{ }^{\circ}$ of $-158 \pm 3 \mathrm{cal} \cdot \mathrm{mol}^{-1} \cdot \mathrm{deg}^{-1}$ ) typically associated with the burial of nonpolar moieties, the $\mathrm{V} 3 \mathrm{H}$ substitution in $\mathbf{3 b}$ appeared to enhance the overall hairpin stability, although being less resistant to the effect of temperature $T_{\mathrm{m}}(\mathbf{3 b}) \ll T_{\mathrm{m}}(\mathbf{3 a})$. A 
truncated version of this strap in hairpin $\mathbf{3 c}$ also demonstrated significant stability with $T_{\mathrm{m}} \sim 62{ }^{\circ} \mathrm{C}$ and a $\Delta G_{\mathrm{F}}{ }^{\circ}=-0.87 \mathrm{kcal} / \mathrm{mol}$. Overall, hairpin $3 \mathbf{c}$ presented the similar stability to the slightly longer HP7 construct (Table 1, entry 3), which led us to speculate that an ionic pair at the terminal HB-site might provide a new framework for building valuable $\beta$-straps. In contrast to the folding of $\mathbf{2 a}$, which is associated with an extended hydrophobic packing (highly enthalpically favorable, $\Delta H_{\mathrm{F}}{ }^{\circ} \sim-6 \mathrm{kcal} / \mathrm{mol}$ ), hairpin 3a carries a smaller enthalpic contribution $\left(\Delta H_{\mathrm{F}}{ }^{\circ} \sim-4 \mathrm{kcal} / \mathrm{mol}\right)$, likely to be compensated by an additional conformational flexibility from the salt-bridge. ${ }^{37}$ Indeed, such Coulombic interaction persistent over long distances could conceivably tame the overall hairpin fraying and afford the appropriate flexibility to achieve an optimal geometry within the neighboring EtF W/W aromatic interaction. ${ }^{38}$ Taken together, our thermodynamic results imply that the RWVW $\cdots$ WVWE strap sequence of $\mathbf{3 a}$ was optimal in stabilizing short $\beta$-hairpins.

This strap was further evaluated on hairpins $\mathbf{3 d - f}$ with long loops of variable plasticity. The CD signature from the W/W exciton maxima at $228 \pm 1 \mathrm{~nm}$ was also observed for all constructs 3d-f despite in lower intensity. As expected, the entropic cost associated with the folding of a polyglycinyl loop in $\mathbf{3 d}$ is relatively large in comparison to $3 \mathbf{e}\left(\mathrm{T} \cdot \Delta \Delta S_{\mathrm{F}}{ }^{\circ}(\mathbf{3 d} / \mathbf{3 e})\right.$ $=-3.53 \mathrm{kcal} / \mathrm{mol}$ ). Even so, hairpin 3d is extremely well folded with a $T_{\mathrm{m}}$ of $\sim 52{ }^{\circ} \mathrm{C}$ and a $\chi_{\mathrm{F}}$ of $88 \%$ at $18{ }^{\circ} \mathrm{C}(291 \mathrm{~K})$. In contrast, hairpin $3 \mathrm{e}$ bearing a conformationally constrained loop of "random" sequence (pembrolizumab H3 loop model, see Figure 1B) proved less stable, as shown by the CD-melt in Figure 3A. To reduce both hydrophobicity and rigidity in the loop, an F9G substitution was evaluated at the L4 position of 3f. Given that the heat capacities calculated for the transitions of hairpins $\mathbf{3 e}$ and $\mathbf{3 f}$ were comparable, the release of loop strain in $\mathbf{3 f}$ likely contributed to enhance its folding. Overall, the CD melts revealed that short hairpins $\mathbf{2 a}, \mathbf{3 a}$, and $\mathbf{3 b}$ are "hyperstable" with a long plateau of thermal stability from 0 to $\sim 50{ }^{\circ} \mathrm{C}$. Below $50{ }^{\circ} \mathrm{C}$, such foldings exist in a dynamic equilibrium of stable conformational states ( $>80 \%$ folded, vide infra NMR data), which affect the cooperativity of the transitions (continuum of discrete steps). ${ }^{25 b}$ On the other hand, both hairpins bearing flexible loops $\mathbf{2} \mathbf{b}$ and $\mathbf{3 d}$ have a more ideal all-or-none transition than their constrained counterparts 2a and 3e. This result might be explained by the lesser change of entropy in flexible loops between folded and unfolded states.

Thermostability curves are usually applied in the analysis of protein stability to estimate both entropic and enthalpic contributions induced by mutations to the proteins' folding free energy. ${ }^{40}$ To rationalize the differences between $\beta$-straps 1-3 and inform their rational design, such plots of temperature dependence on unfolding free energy $\Delta G_{\mathrm{F}}(\mathrm{T})$ were analyzed (Figure 3B). ${ }^{40}$ The thermodynamic parameters calculated from the two-state model approximation (Figure 3C) were applied to plot these thermostability curves, which can be extrapolated outside the range of experimental temperatures. Thermostability curves have typical parabolic shapes (if $\Delta C_{\mathrm{pF}}{ }^{\circ} \neq 0$ ) that intercept the temperature axis $\Delta G_{\mathrm{F}}(\mathrm{T})=0$ ) at two different temperatures characteristic of cold and thermal denaturations ( $T_{\mathrm{C}}$ and $T_{\mathrm{m}}$ ). At the parabolic maxima, the temperature $T^{*}$ of maximal stability and free energy $\Delta G_{\mathrm{F}} *$ can be determined for each hairpin (Figure 3B,C) ${ }^{41}$ Indeed, at $T^{*}, \Delta S_{\mathrm{F}}{ }^{*}=0$ resulting in $\Delta G_{\mathrm{F}} *=\Delta H_{\mathrm{F}} *$. The differences in enthalpy $\Delta \Delta H_{\mathrm{F}} *$ between hairpins of the identical loop sequence (i.e., NPATGK) were therefore readily compared to estimate the net contribution 
of straps on the overall secondary structure's thermostability. As shown in Figure 3C, the RWVW $\cdots$ WVWE strap performed well in hairpins 3a-c with $\Delta \Delta H_{\mathrm{F}} *$ of -1.19 to $-1.76 \mathrm{kcal} / \mathrm{mol}$, while the Ac-WVW $\cdots \mathrm{WVW}-\mathrm{NH}_{2}$ strap in 2a was the most stabilizing motif with a $\Delta \Delta H_{\mathrm{F}} *$ of $-2.42 \mathrm{kcal} / \mathrm{mol}$. Another significant phenomenon observed from the thermostability curves is the parabolas' curvatures. ${ }^{49}$ Even if $\mathbf{2 a}$ and $\mathbf{3 b}$ are the most stable hairpins $\Delta G_{\mathrm{F}} *$ of -2.50 and $-1.84 \mathrm{kcal} / \mathrm{mol}$ ), the narrower parabolic curvature of their thermostability curves implies that these hairpins have a small range of thermal stability. On the other hand, the wider curvatures observed in the case of $\mathbf{3 c}$ and $\mathbf{3 a}$ suggest that these hairpins absorb more efficiently heat energy for the same increase in temperature (thermostable). This phenomenon can be explained by the fact that hairpins $\mathbf{3 a}$ and $\mathbf{3} \mathbf{c}$ have the smallest $\Delta C_{\mathrm{pF}}{ }^{\circ}$ of -53 and $-106 \mathrm{cal} \cdot \mathrm{deg}^{-1} \cdot \mathrm{mol}^{-1}$, respectively, which ultimately is a consequence of having a smaller hydrophobic surface exposed to water. On the contrary, even if the $\mathrm{V} 3 \mathrm{H}$ mutation created additional contact interactions in hairpin $\mathbf{3 b}$ (i.e. higher fraction folded), the narrower curvature of the thermal stability parabola confirms that the enthalpic contribution of such electrostatic interactions weakened rapidly upon the effect of heat. ${ }^{42}$ The aforementioned entropy held by the loop also affects the thermal stability of longer hairpins and the cooperativity of the unfolding transitions. The large entropic energy contained in the polyglycinyl loop of hairpin $\mathbf{3 d}$ likely contributed to its sharp thermal denaturation thus resulting in a narrow range of thermal stability. Conversely, the wider curvature of the $\Delta G_{\mathrm{F}} *$ plot for $\mathbf{3 e - f}$ (shift of $T^{*}$ ) demonstrated how compactness and local side-chain interactions in more conformationally constrained loops can preclude the rapid thermal denaturation. This effect culminated in the stability of hairpin $\mathbf{3 f}$ (slightly less rigid and hydrophobic than $3 \mathrm{e}$ ) with the largest $\Delta G_{\mathrm{F}} *$ of $-3.18 \mathrm{kcal} / \mathrm{mol}$ and $T_{\mathrm{m}}$ of $46.7 \pm 0.1^{\circ} \mathrm{C}$.

\section{Structural and Conformational Analysis by NMR Spectroscopy.}

To confirm the secondary structures suggested by the CD study, a careful structural assignment and conformational analysis were secured by NMR spectroscopy. ${ }^{43}$ Detailed NMR studies of hairpins $1-3$ at $18{ }^{\circ} \mathrm{C}(291 \mathrm{~K})$ were carried in a mixture of phosphate buffer ( $\mathrm{pH}$ 6.5) with $\mathrm{D}_{2} \mathrm{O}$, with small proportions of additives (DMSO- $d_{6}$, or $\mathrm{CD}_{3} \mathrm{OH}$ ) in rare cases, at concentrations ca. 1-20 mM with DSS as the internal standard for chemical shifts. Signals assignments were obtained on the basis of a set of ${ }^{1} \mathrm{H}$ and TOCSY spectra (for intraresidue connectivities), NOESY spectra (for vicinal and interstrand backbone connectivities), and HSQC spectra (for $\mathrm{H}_{a}$ to $\mathrm{C}_{a}$ connectivities and $\mathrm{W}$ side-chains assignments). ${ }^{34}$ First, chemical shift deviations (CSDs) were calculated for all of the $\mathrm{H}_{\mathrm{N}}$ and $\mathrm{H}_{a}$ proton resonances in each hairpin 1-3 (Figure 4). ${ }^{44}$ Average CSDs obtained for the synthetic unfolded constructs SI-RC1-4 were in each case close to zero (avg. $|\Delta \delta \mathrm{H}|$ $<0.2 \mathrm{ppm}$ ) indicating the absence of the secondary structure as expected for coil-like structures. ${ }^{34,45}$ These results further validated our unfolded models used to calibrate the unfolded baselines in the CD-melt analysis. For constructs 1a,b, the overall chemical shift dispersion of $\mathrm{H}_{\mathrm{N}}$ and $\mathrm{H}_{a}$ signals is small, and CSDs characteristic of $\beta$-hairpins (upfield in the loop and downfield in strands) are not observed (Figure 4A). Furthermore, the W(S $-2) / \mathrm{W}(\mathrm{S}+2)$ pair in 1a was characterized by upfield shifts of 0.58 and $0.45 \mathrm{ppm}$ for the $\mathrm{H}_{\mathcal{E} 3}$ and $\mathrm{H}_{\beta 3}$ signals of the "edge" $\mathrm{W}(\mathrm{S}-2)$ residue indicative of a reverse EtF arrangement characteristic of misfolding (instead of FtE interaction). In hairpin 1c, the addition of an $\mathrm{F} / \mathrm{F}$ pair at the $\mathrm{S} \pm 2$ positions flanking the loop enabled the $\beta$-strap to actually fold ${ }^{46}$ in 
a similar fashion to the [2:2]-hairpins reported by Andersen. An FtE W(S - 4)/W(S + 4) interaction was plainly observed in this case, with CSDs for $\mathrm{W}(\mathrm{S}+4) \Delta \delta \mathrm{H}_{\beta 3}$ and $\Delta \delta \mathrm{H}_{\mathcal{E} 3}$ of -0.45 and $-1.62 \mathrm{ppm}$, respectively, as well as a distinctively large upfield $\mathrm{G}_{14 \mathrm{H}_{\mathrm{N}}}$ proton shift ( $\delta 6.33 \mathrm{pm}$ corresponding to a CSD of $-1.78 \mathrm{ppm}$ from its random coil value). Overall, the backbone $\mathrm{H}_{\mathrm{N}}$ and $\mathrm{H}_{a}$ CSDs from the Ac-W $\cdots$ WTG-NH $\mathrm{N}_{2}$ strap motif in 1c revealed a pattern consistent with a $\beta$-sheet register. The folded conformation of hairpin $1 \mathbf{c}$ was further supported by a set of cross-strand NOESY correlations (Figure S19).

Earlier studies on [2:2]-hairpins established that the extent of chemical shift splitting between glycine methylene signals in ${ }^{1} \mathrm{H}$ NMR spectra $\left(\Delta \delta \mathrm{H}_{a / a}\right.$ (Gly)) can be exploited to quantify the $\%$-folding of $\beta$-hairpins. ${ }^{43 \mathrm{a}, 45 \mathrm{c}, 47}$ These two $\mathrm{H}_{\alpha} / \mathrm{H}_{\alpha}$, diastereotopic protons experience a different chemical environment relative to the ratio of equilibrating conformers on the NMR time scale. Thus, a greater separation is indicative of a larger folded population. This local folding probe was notably applied by Horne and Del Valle to [4:4]/[4:6]-hairpins featuring the NPATGK reverse-turn locus, by measuring the $\Delta \delta \mathrm{H}_{a / a}$ (Gly) separation of $\mathrm{G}(\mathrm{L} 4) .{ }^{27,48} \mathrm{In}$ a series of macrocyclic peptides, the largest $\Delta \delta \mathrm{H}_{a / a} \mathrm{G}(\mathrm{L} 4)$ value of $0.33 \mathrm{ppm}$ was attributed to $100 \%$-folding and used as a benchmark for the "fully" folded hairpin. Strikingly, several synthetic hairpins from our study (e.g., 1c, 2a, 3a-c) have shown even larger shifts $0.46-0.55 \mathrm{ppm}$ (see Table 1 ). We therefore re-estimated the folded population for the loops of hairpins 1-3 based on a $0.55 \mathrm{ppm}$ splitting for the $\mathrm{G}(\mathrm{L} 4) \mathrm{H}_{a} / a^{\prime}$, resonances as the $>99 \%$-folded ref $49 . \Delta \delta \mathrm{H}_{a / a} \mathrm{G}(\mathrm{L} 4)$ values of 0.23 and $0.50 \pm 0.01 \mathrm{ppm}$ observed at $291 \mathrm{~K}$ for $1 \mathrm{a}$ and $1 \mathrm{c}$ correspond to a local folded population estimate of $42 \pm 4$ and $91 \pm$ $2 \%$, respectively. Although the poor solubility of constructs $\mathbf{2 a - b}$ in water limited our NMR interpretations, the folding of $\mathbf{2} \mathbf{b}$ was found minimal. Indeed, $\mathrm{H}_{\mathrm{N}}$ and $\mathrm{H}_{a}$ CSDs in construct 2b were mostly insignificant throughout, and the local loop folding was characterized by a $\Delta \delta \mathrm{H}_{a / a} \mathrm{G}(\mathrm{L} 4)$ of $0.03 \mathrm{ppm}$ corresponding to $6 \pm 33 \%$ of folding at $291 \mathrm{~K}$ (Table 1, entry 10). On the contrary, hairpin 2a was $93 \pm 2 \%$-folded and characterized by high CSDs for the tryptophans side-chain signals due to two FtE W(S \pm 4$)$ and Etf $\mathrm{W}(\mathrm{S} \pm 2)$ interstrand interactions. For the turn-flanking edge $\mathrm{W}(\mathrm{S}-2)$ residue, $\mathrm{H}_{\mathcal{E} 3}, \mathrm{H}_{\beta 3}$, and $\mathrm{H}_{\delta 1}$ experienced upfield ring current shifts as large as $1.22,0.95$, and $0.60 \mathrm{ppm}$, due to aromatic shielding, whereas the edge $\mathrm{C}$-terminal $\mathrm{W}(\mathrm{S}+4)$ residue displayed upfield shifts of 1.25, 0.99, and $0.44 \mathrm{ppm}$ for the same proton signals (Figure 4, bottom panel). These NMR structuring shifts are similar to those reported for the HP7 and Trpzip4 hairpins, thus confirming the efficiency of the truncated $\beta$-strap. ${ }^{50}$ The folded nature of hairpin $\mathbf{2 a}$ was further supported by various cross-strand and long-range NOESY correlations (Figure S20). Collectively, NMR and CD data obtained at $291 \mathrm{~K}$ revealed that hairpin $2 \mathbf{a}$ is well folded with $\chi_{\mathrm{F}}>90 \%$.

As shown by the trend of thermodynamic stability observed in the CD melts, the RW(VW) $\cdots$ (WV)WE $\beta$-strap proved to be superior (e.g., 3a-c) throughout the NMR study (Figure 4B). Indeed, ${ }^{1} \mathrm{H}$ NMR signals for both $\mathrm{H}_{\mathrm{N}}$ at $\mathrm{HB}$ sites and $\mathrm{H}_{a}$ at NHB-sites within the $\beta$-strap were highly dispersed and experienced significant downfield shifts $(\sim 1.5 \mathrm{ppm}$ on average). ${ }^{45 a}$ The strong $\mathrm{FtE}$ and $\mathrm{EtF} \mathrm{W} / \mathrm{W}$ interactions at the $\mathrm{S} \pm 4$ and $\mathrm{S} \pm 2$ positions were further rationalized by the formation of a more compact hydrophobic cluster. Distinctive NMR shifts with CSDs of -1.49 and -1.16 ppm for $\mathrm{H}_{\beta 3},-0.62$ and -0.32 ppm for $\mathrm{H}_{\delta 1}$, and -1.21 and -1.19 for $\mathrm{H}_{\mathcal{E} 3}$ observed at the respective $\mathrm{S}-2$ and $\mathrm{S}+4$ edge sites of hairpin 
3a denoted that the indole rings of these tryptophans experienced a significant ring current shift. A similar range of shifts was observed for the W(S - 2) of the shorter hairpin 3c. As shown in Figure 5, strong NOESY correlations between the $\mathrm{H}_{\mathrm{N}}$ protons of $\mathrm{A}(\mathrm{L} 2), \mathrm{T}(\mathrm{L} 3)$, $\mathrm{G}(\mathrm{L} 4)$, and $\mathrm{K}(\mathrm{S}+1)$ secure the overall loop conformations in both 3a and 3c. Correlations between the $\mathrm{W}(\mathrm{S}-2) \mathrm{H}_{\zeta 2}$ and both $\mathrm{G}(\mathrm{L} 4) \mathrm{H}_{a}$ and $\mathrm{H}_{\mathrm{N}}$ were also consistent in both hairpin spectra. Both $\mathrm{S} \pm 4$ and $\mathrm{S} \pm 2 \mathrm{~W} / \mathrm{W}$ interactions were also confirmed by a combination of long-range side-chain to side-chain NOESY correlations. NOESY correlations between the $\mathrm{W}(\mathrm{S}+4) \mathrm{H}_{\mathcal{E} 3}$ and $\mathrm{H}_{\zeta 3}$ with the $\mathrm{R}(\mathrm{S}-5) \mathrm{H}_{a}$ proton suggest that the $\mathrm{C}-/ \mathrm{N}$-termini fraying for this hairpin is minimal at $291 \mathrm{~K}$. More importantly, we found several intense $\mathrm{H}_{\mathrm{N}}-\mathrm{H}_{\mathrm{N}}$ NOESY correlations between $\mathrm{N}(\mathrm{S}-1)$ and $\mathrm{K}(\mathrm{S}+1)$ residues in 3a and $\mathbf{3 c}$ and an $\mathrm{H}_{\mathrm{N}}-\mathrm{H}_{a}$ interaction $\mathrm{N}(\mathrm{S}-1)$ to $\mathrm{W}(\mathrm{S}+2)$ in $\mathbf{3 a}$ supporting the formation of an interstrand hydrogen bond network in the $\beta$-strap. Finally, the NOESY correlation between the $\mathrm{S} \pm 3$ positions $\mathrm{VH}_{\mathrm{N}}$ in 3a definitely established the presence of a $\beta$-sheet register within a [4:6]-hairpin (Figure 5). Overall, folded populations of 84,93 , and $>99 \%( \pm 2 \%)$ were estimated from the $\Delta \delta \mathrm{H}_{\text {a/a }} \mathrm{G}(\mathrm{L} 4)$ values in the loops of hairpins $\mathbf{3} \mathbf{c}, \mathbf{3 a}$, and $\mathbf{3 b}$, respectively.

[10:12]-hairpins 3d-f bearing the longest loops were also extensively characterized by combinations of NMR experiments. Excitingly, in both examples of flexible and rigid loops (3d and 3f), a large positive CSD pattern across the $\beta$-strap residues unambiguously established the foundation of a $\beta$-hairpin register (Figure $4 \mathrm{C}$ ). In the case of hairpin $\mathbf{3 d}$ experiencing the most flexibility, both $\mathrm{H}_{\mathrm{N}}$ and $\mathrm{H}_{a}$ of the strap residues resonated downfield (CSD of 0.30-2.15 ppm), while hydrogens of the loop residues witnessed small CSDs $(<0.10 \mathrm{ppm})$. Except for Gly residues flanking the strap edges, $\Delta \delta \mathrm{H}_{a / a}, \mathrm{G}$ of $0 \mathrm{ppm}$ was observed in the loop due to its innate flexibility and a lack of asymmetric environment. By analogy to the shorter loops, folding of $\mathbf{3 d}$ was estimated to be $>99 \pm 2 \%$ at $291 \mathrm{~K}$ given a $\Delta \delta \mathrm{H}_{a / a}, \mathrm{G}(\mathrm{S}+1)$ of $0.55 \mathrm{ppm}$. CSDs of -0.94 and $-1.07 \mathrm{ppm}$ for $\mathrm{H}_{\beta 3},-0.44$ and $-0.31 \mathrm{ppm}$ for $\mathrm{H}_{\delta 1}$, and -1.25 and $-1.15 \mathrm{ppm}$ for $\mathrm{H}_{\mathcal{E} 3}$ observed at the respective $\mathrm{W}(\mathrm{S}-$ 2) and $\mathrm{W}(\mathrm{S}+4)$ of $\mathbf{3 d}$ were comparable to the ring current shifts observed in hairpins 3a-c, which confirmed that both W/W pairs were creating FtE arene interactions. As shown in Figure 5, NOESY correlations between $\mathrm{R}^{1} \mathrm{H}_{a}$ with $\mathrm{W} 17 \mathrm{H}_{\varepsilon 3}$ and $\mathrm{W} 2 \mathrm{H}_{\varepsilon 3}$ with $\mathrm{W} 15 \mathrm{H}_{\beta}$ in hairpin $\mathbf{3 d}$ are stronger than in $\mathbf{3 a}$, and the long-range interstrand correlation of $\mathrm{W}_{2} \mathrm{H}_{a}$ with $\mathrm{W} 17 \mathrm{H}_{\mathrm{N}}$ further supported a hairpin fold. These results suggested that strap $\mathbf{3}$ afforded enough stabilization to offset the flexibility of the polyglycinyl loop. Seemingly, even if a high plasticity typically results in slower kinetics of nucleation, ${ }^{51}$ the thermodynamics of such systems (i.e., 3d vs $\mathbf{3 e}$ ) are more favorable to a hairpin structuration due to a more flexible strand alignment. In regards to the more strained hairpin 3e, ${ }^{1} \mathrm{H}$ NMR spectra at 291 $\mathrm{K}$ displayed overlapping and broader signals in the $\mathrm{H}_{\mathrm{N}}$ region with small CSD values (avg. of $0.30 \mathrm{ppm}$ ) indicative of a rapid sampling of multiple conformer populations, which is not surprising considering that $298 \mathrm{~K}$ was the melting temperature of $\mathbf{3 e}$ determined by $\mathrm{CD} .{ }^{34}$ In stark contrast, the rigid hairpin $\mathbf{3 f}$ (one glycine mutation in the loop) was remarkably well folded with downfield deviations for $\mathrm{H}_{\mathrm{N}}$ signals within the strap (CSD of 0.47-1.97 ppm) strikingly similar to 3d suggesting a fine alignment. Large CSDs of -0.99 and $-1.28 \mathrm{ppm}$ for $\mathrm{H}_{\beta 3},-0.67$ and $-0.21 \mathrm{ppm}$ for $\mathrm{H}_{\delta 1}$, and $-1.01 \mathrm{ppm}$ for both $\mathrm{H}_{\mathcal{E} 3}$ were also observed at the respective $\mathrm{W}(\mathrm{S}-2)$ and $\mathrm{W}(\mathrm{S}+4)$ positions. In addition, a number of medium to strong NOESY correlations within the strap were observed as exemplified by the $\mathrm{V}^{3} \mathrm{H}_{\mathrm{N}}$ and 


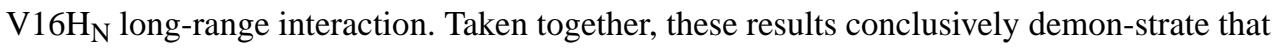
3f is a well-structured hairpin with the stabilizing edge tryptophan side chains at residues $\mathrm{W}(\mathrm{S}-2)$ and $\mathrm{W}(\mathrm{S}+4)$ in a zipper-like motif. Along those lines, the loop \%-folding in $\mathbf{3 f}$ was estimated to be $\sim 55 \pm 2 \%$ at $291 \mathrm{~K}$ based on the glycine shifts at the G(L7) position $\left(\Delta \delta \mathrm{H}_{a / a}\right.$, of $\left.0.30 \mathrm{ppm}\right)$. Collectively, structural NMR data demonstrated that the RWVW $\cdots$ WVWE strap 3 was the most efficient hairpin-folding manifold for short and long loops of varying plasticity.

\section{CONCLUSIONS}

Accessing larger macrocyclic peptides is an emerging trend to build mini protein-like structures thermodynamically stable in water. ${ }^{52}$ However, the identification of $\beta$-hairpins that closely mimic the native fold of protein and antibody loops remain challenging due to the large entropic penalty associated with their conformational folding. In this study, a de novo design of short $\beta$-straps featuring a combination of ionic interaction with a zipper motif provided a benchmark manifold to fold hairpin architectures with long loops of variable plasticity (up to 10 -mer). Several novel $\beta$-strap motifs of minimalist length were crafted by combining $\beta$-strand $+\beta$-cap to generate hairpins containing loops of variable length, plasticity, and turn propensity. Although strap Ac-WVW $\cdots \mathrm{WVW}-\mathrm{NH}_{2} 2$ was found to be highly stabilizing, the hydrophobic cluster modeled upon the Trpzip molecules (large $\Delta C_{\mathrm{pF}}{ }^{\circ}$ of $-159 \pm 17 \mathrm{cal} \cdot \mathrm{deg}^{-1} \cdot \mathrm{mol}^{-1}$ ) leads to a poor and unpractical solubility in water. This motif was further optimized in strap RW(VW) $\cdots(\mathrm{WV}) \mathrm{WE} 3$ by combining the folding driving force associated with the W/W cluster hydrophobicity to the long-distance stabilizing features of a salt-bridge ${ }^{38,39}$ positioned at hairpins' termini. The CD-exciton signature at $228 \mathrm{~nm}$ from two W/W EtF interactions as well as the large NMR upfield CSDs (1.16-1.49 ppm and 1.19-1.21 ppm for $\mathrm{H}_{\beta 3}$ and $\mathrm{H}_{\mathcal{\varepsilon} 3}$ ) and long-range NOESY correlations reported for 3a conclusively demonstrated that well-folded hairpins were formed (89-93\% fold).

Finally, the strong enthalpic contribution from $\beta$-strap $3\left(\Delta \Delta H_{\mathrm{F}} *\right)$ was able to remarkably offset the entropic penalty associated with the wealth of conformations generated by longer 10-mer loops. ${ }^{17}$ To our knowledge, this is the first observation of a short $\beta$-strap (8-mer long) able to structure loops longer than the strap itself (up to $88 \%$ fold, $T_{\mathrm{m}}$ of $25-52$ $\left.{ }^{\circ} \mathrm{C}\right)$. Strap 3 largely outperforms the technology previously developed by Andersen for long-loop closure (16-mer $\beta$-cap- $\beta$-strand).${ }^{16}$ Collectively, these results suggest that the specific site positioning and combination of a terminal salt-bridge with van der Walls and $\mathrm{CH}-\pi$ hydrogen bond interactions from the two EtF W/W pairs within the strap are an efficient hairpin-folding manifold. Our results suggest that $\beta$-strap 3 might found useful applications to fold hairpin architectures with long loops of varying plasticity and random sequences. Ultimately, we anticipate that the present study will provide the foundation for the development of long hairpin foldings as an attractive alternative to macrocyclic peptides for the mimicry of proteins and antibodies. 3,53 


\section{EXPERIMENTAL SECTION}

\section{General Information.}

All reagents, Fmoc-amino acids, and resins used in the present paper were purchased from Chemimpex and Millipore Sigma. All bulk solvents were acquired from Fischer Scientific. Peptides 1c, 3a-c were purchased from Peptide 2.0 Inc. Peptides, 1a-b, 2a-b, 3c-d, and SI-RC1-2 were synthesized using a standard automatized Fmoc-SPPS technique (solidphase peptide synthesis) on a Protein Technologies PS-3 peptide synthesizer. Syntheses were accomplished either on a Rink amide resin of medium loading $(0.27 \mathrm{mmol} / \mathrm{g})$ or Fmoc-Glu-Wang resin (0.4 mequiv/g). Random coil model peptides SI-RC3a/b and SI-RC4 were synthesized on a manual peptide synthesizer, using a Fmoc-FPPS (fast-parallel peptide synthesis) technique, on a Rink amide resin of medium loading $(0.27 \mathrm{mmol} / \mathrm{g})$ and FmocGlu-Wang resin (0.4 mequiv/g). Our synthetic hairpin peptides have a net charge of -1 , +1 , or +2 (from loop sequence) to enhance water solubility and prevent aggregation. Structural assignments were made by a set of NMR spectra including TOCSY, NOESY, HSQC, and HMBC experiments recorded on a Varian Mercury500 (500 MHz) spectrometer and processed using the Vnmrj 4.2 software.

\section{Peptide Synthesis.}

General Procedure for Peptide Synthesis Via Fmoc-SPPS.-Syntheses were carried out at room temperature in anhydrous DMF using the resins described above (200-300 mg, 1.0 equiv, as reported below for each peptide) by successive iterations of deprotection/coupling. Vials of each Fmoc-protected $a$-amino acid (4.0 equiv) were prepared with HBTU (4.4 equiv) and HOBt (4.4 equiv) neat. For each iteration, the deprotection/coupling sequence entails (1) wash of the resin with DMF $(3 \times 5.0 \mathrm{~mL})$ for 0.5 min each, (2) Fmoc-deprotection run twice using an excess of piperidine in DMF (20\% $\mathrm{v} / \mathrm{v}, 5.0 \mathrm{~mL})$ for $5 \mathrm{~min}$ each, (3) wash with DMF $(6 \times 5.0 \mathrm{~mL})$ for $0.5 \mathrm{~min}$ each, $(4)$ the cocktail from the entire vial (described above) was dissolved with $\mathrm{N}$-methylmorpholine in DMF (3.0 mL, $4 \mathrm{M})$ and added for a 40 min coupling, (5) wash with DMF $(3 \times 5.0$ $\mathrm{mL}$ ) for $0.5 \mathrm{~min}$ each, finalized the sequence. After the final $\mathrm{N}$-terminal coupling, a final Fmoc-deprotection was achieved (step 2). The resulting peptides attached to the resin were washed with $\mathrm{CH}_{2} \mathrm{Cl}_{2}(2 \times 10 \mathrm{~mL})$, and the resin was dried under vacuum before storage under an argon atmosphere at $-78{ }^{\circ} \mathrm{C}$ until cleavage.

General Procedure for Peptide Synthesis Via Fmoc-FPPS.-Syntheses were carried out at room temperature in anhydrous DMF using the resins described above (200-300 mg, 1.0 equiv, as reported below for each peptide) by successive iterations of deprotection/coupling. For each iteration, the deprotection/coupling sequence entails (1) resin swelling in DMF (10 mL) for $10 \mathrm{~min}$, (2) Fmoc-deprotection run twice using an excess of piperidine in DMF ( $20 \% \mathrm{v} / \mathrm{v}, 5.0 \mathrm{~mL})$ for $2 \mathrm{~min}$ each, (3) wash with DMF $(3 \times 5.0$ $\mathrm{mL}$ ) for $0.5 \mathrm{~min}$ after each deprotection, (4) coupling reaction run twice for $5 \mathrm{~min}$ each by adding in order Fmoc-amino acid stock solution (5 equiv in $5 \mathrm{~mL}$ DMF), HATU stock solution (5 equiv in $5.0 \mathrm{~mL}$ DMF), and DIEA (10 equiv), and (5) wash with DMF ( $3 \times$ $5.0 \mathrm{~mL}$ ) for $5 \mathrm{~min}$ after each coupling reaction. After the final $\mathrm{N}$-terminal coupling, a final Fmoc-deprotection was achieved (step 2). The resulting peptides attached to the resin were 
washed with $\mathrm{CH}_{2} \mathrm{Cl}_{2}(2 \times 10 \mathrm{~mL})$, and the resin was dried under vacuum before storage under an argon atmosphere at $-78{ }^{\circ} \mathrm{C}$ until cleavage.

General Procedure for Peptide Deprotection and Cleavage from Resins.-The same protocol of simultaneous resin cleavage and sidechains' deprotection was applied to both resins. The dried resin was suspended in a cleavage cocktail (TFA/thioanisole/EDT/ anisole, 90:5:3:2 v/v, $1.0 \mathrm{~mL}$ per $20 \mathrm{mg}$ of resin) and shaken for $1.5 \mathrm{~h}$ at RT. The mixture was filtered to remove the resin and the mother liquor was evaporated on a rotary evaporator. The crude peptides $(250 \mathrm{mg})$ were precipitated in cold ether $(40 \mathrm{~mL})$, then centrifuged, and washed with cold ether $(3 \times 40 \mathrm{~mL})$. The resulting crude peptides were solubilized in water and lyophilized before being stored as dry powders under an argon atmosphere at $-78{ }^{\circ} \mathrm{C}$.

All lyophilized crude peptides were analyzed by analytical reverse-phase high-performance liquid chromatography (RP-HPLC) Hitachi L-7000 series equipped with an XBridge BEH $\mathrm{C}_{18}$ column $(130 \AA, 10 \mu \mathrm{m}, 4.6 \mathrm{~mm} \times 250 \mathrm{~mm})$. HPLC grade acetonitrile and deionized water, each containing $0.1 \%$ trifluoracetic acid, were used for analytical and semipreparative RP-HPLC. Each peptide was analyzed using a gradient from 10 to $50 \%$ of acetonitrile over 30 min with a flow rate of $1.0 \mathrm{~mL} / \mathrm{min}$ at room temperature and a detection at $220 \mathrm{~nm}$. Yields refer to chromatographically and spectroscopically pure compounds, unless otherwise stated. If required, peptides were purified with a Hitachi L-7000 series HPLC equipped with a semipreparative XBridge BEH $\mathrm{C}_{18}$ column $(130 \AA, 10 \mu \mathrm{m}, 10 \mathrm{~mm} \times 250 \mathrm{~mm}$ ) stationary phase by scaling up the analytical conditions. The pure fraction of peptides was collected and analyzed by analytical RP-HPLC and mass spectrometry using a Microflex LRF matrix-assisted laser desorption ionization time-of-flight (MALDI-TOF) instrument.

\section{Nuclear Magnetic Resonance Data Collection.}

NMR samples were prepared by dissolving the freeze-dried peptide $(\sim 1-2 \mathrm{mg})$ in a mixture of phosphate buffer $(50 \mathrm{mM}, \mathrm{pH} 6.5)$ and $\mathrm{D}_{2} \mathrm{O}(9: 1, \mathrm{v} / \mathrm{v})$ unless otherwise stated, using 2,2-dimethyl-2-silapentane-5-sulfonate (DSS) as the internal standard for chemical shifts (0 $\mathrm{ppm}$ ). Samples were prepared in a range of $3-10 \mathrm{mM}$ of the peptide for ${ }^{1} \mathrm{H}$ NMR, TOCSY (mixing time $80 \mathrm{~ms}$ ), NOESY (mixing time $200 \mathrm{~ms}$ ), and ${ }^{1} \mathrm{H}-{ }^{13} \mathrm{C}$ HSQC experiments and in a range of $10-20 \mathrm{mM}$ to record ${ }^{1} \mathrm{H}-{ }^{15} \mathrm{~N}$ HSQC and $\mathrm{HMBC}$ spectra (with the exception of SI-RC1, 1a, and 1b samples, which were prepared in a range of 10-70 $\mathrm{mM}$ range). A PRESAT experiment was used to suppress the $\mathrm{H}_{2} \mathrm{O}$ solvent signal, to record initial ${ }^{1} \mathrm{H}$ NMR spectra. All spectra were recorded at $291 \mathrm{~K}\left(18{ }^{\circ} \mathrm{C}\right)$ on a Varian Mercury500 (500 $\mathrm{MHz}$ ) spectrometer and processed using the Vnmrj 4.2 software. Signals assignments were obtained on the basis of a set of ${ }^{1} \mathrm{H}$ and TOCSY spectra (for intraresidue connectivities), NOESY spectra (for vicinal and interstrand backbone connectivities), and HSQC spectra (for $\mathrm{H}_{a}$ to $\mathrm{C}_{a}$ connectivities and $\mathrm{W}$ side-chains assignments).

\section{Chemical Shift Deviation (CSDs).}

Chemical shift deviations (or CSD) have been calculated based on a simulated unfolded reference that represents the predicted (calcd.) chemical shift values along the random coil sequence, based on the established work from Poulsen and others. ${ }^{44}$ The calcd. random coils' chemical shifts for the backbone $\mathrm{H}_{a}$ and $\mathrm{H}_{\mathrm{N}}$ protons were obtained from the online 
software available at: https://spin.niddk.nih.gov/bax/nmrserver/Poulsen_rc_CS/. The random coil calcd. $\delta$ values were validated by comparison to the experimental values obtained for SI-RC1-4 $(\triangle \mathrm{CCSD} \mid \leq 0.20 \mathrm{ppm})$. CSDs for each hairpin construct were then calculated according to $\operatorname{CSD}(\mathrm{H})=\delta \mathrm{H}_{\text {exp. }}-\delta \mathrm{H}_{\text {calcd. }}$ and reported in tables (Supporting Information Sections 2-4). Furthermore, CSDs related to the side chains of tryptophan residues have been calculated from the list of known chemical shifts reported on the BMRB database (Biological Magnetic Resonance Bank) for Trp in random coils: http://www.bmrb.wisc.edu/ ref_info/pentapeptide.tbl. This list of chemical shifts (Trp random coils) has been previously validated by Andersen et al. ${ }^{26}$

\section{Far-UV Circular Dichroism (CD) Spectroscopy.}

Peptide solutions were prepared at the $20-100 \mu \mathrm{M}$ concentration range in phosphate buffer (15 mM, pH 6.5), with the addition of $\mathrm{MeOH}$ (up to $50 \% \mathrm{v} / \mathrm{v}$ ) if required to increase solubility. Each sample concentration was determined accurately by measuring the solution UV-absorbance using a JASCO V-670 spectrophotometer based on the combined molar absorptivity of Trp and Tyr residues at $280 \mathrm{~nm}\left(\varepsilon_{280}=5580 \mathrm{M}^{-1} \cdot \mathrm{cm}^{-1}\right.$ per Trp, $\varepsilon_{280}=1280$ $\mathrm{M}^{-1} \cdot \mathrm{cm}^{-1}$ per Tyr). CD spectra were recorded on a JASCO J-810 Spectropolarimeter with a temperature controller module JASCO PFD-425S. In brief, raw CD data were recorded in mdeg from 185 to $270 \mathrm{~nm}$ every $0.1 \mathrm{~nm}$, and CD spectra of the blank solutions were subtracted for baseline correction. Spectra were smoothed with the baseline set to zero between 260 and $270 \mathrm{~nm}$ and the ellipticity scale was converted into molar ellipticity (deg.cm ${ }^{2} . \mathrm{dmol}^{-1}$ ) using SpectraGryph 1.2. ${ }^{54}$ To obtain melting curves representing peptide unfolding transitions, variable-temperature $\mathrm{CD}$ experiments were recorded. For SI-RC1, 1a, $\mathbf{1 b}$, and $2 \mathrm{~b}$, VT-CD spectra were manually recorded every $5{ }^{\circ} \mathrm{C}$ from 5 to $95^{\circ} \mathrm{C}$ with a 10 min stabilization between each temperature. $\mathrm{CD}$ spectra of the blank solution were recorded similarly and subtracted to the peptide spectra at each temperature. Molar ellipticity values at $228 \mathrm{~nm}$ (Trp exciton band) were plotted to obtain experimental melting curves. For SI-RC2-4, 1c, 2a, and 3a-e, the temperature ramp was controlled automatically from 5 to $95^{\circ} \mathrm{C}$ with a ramp speed of $0.75{ }^{\circ} \mathrm{C} / \mathrm{min}$. Intensity values at $228 \mathrm{~nm}$ were recorded by the instrument every $0.1{ }^{\circ} \mathrm{C}$ to obtain the desired raw melting curves. Likewise, intensities for the corresponding blank solutions were recorded and subtracted to afford the experimental melting curves' output. These thermal denaturation curves were reported in molar ellipticity $\left(\mathrm{deg} \cdot \mathrm{cm}^{2} \cdot \mathrm{dmol}^{-1}\right)$ and normalized against the number of tryptophan pairs present in the peptide construct $\left([\theta(\mathrm{T})]_{228} / p \operatorname{Trp}\right.$ ) for comparison (see Figure $\mathrm{S} 2$ ). Finally, a nonlinear least square fitting routine program has been developed in Origin 9.0 (Originlab Corporation) to compute the best-fitted melting curves to the raw $[\theta(T)]_{228}$ data by using the thermodynamic Gibbs-Helmholtz equation of free-energy variation for a two-state model (eq S2). A detailed description for obtaining the $\%$-folding best-fitted curves, all calculations, $\Delta G^{\circ}, \Delta H^{\circ}, \Delta S^{\circ}$, $\Delta C_{\mathrm{p}}^{\circ}$, and $T_{\mathrm{m}}$ thermodynamic values is given in the Supporting Information Section 1.

\section{Supplementary Material}

Refer to Web version on PubMed Central for supplementary material. 


\section{ACKNOWLEDGMENTS}

The authors are very grateful for the financial support from the National Institutes of Health (NIGMS Grant: R21GM132754 to S.P.R., A.D.R., and G.Z.). The authors thank Dr. M. Cudic and Dr. D. Du from Florida Atlantic University for the use of their peptide synthesizers and Dr. E. Rivera from the University of South-Florida for the training of A.D.R. and his assistance with the acquisition of 2-D NMR data. The authors thank Dr. X. Kong from the SCRIPPS-Florida NMR facility for the HSQC spectral acquisition of peptide 3f. The authors also thank Laura Viala from the University of Quebec at Chicoutimi for some preliminary data on peptide synthesis supported by a Mitacs Globalink internship funding and Dr. G. Theodore from Theogen Corp. for manuscript proofreading and editing.

\section{REFERENCES}

(1) (a). Barron AE; Zuckermann RN Bioinspired polymeric materials: in-between proteins and plastics. Curr. Opin. Chem. Biol 1999, 3, 681-687. [PubMed: 10600724] (b)Sun J; Zuckermann RN Peptoid Polymers: A Highly Designable Bioinspired Material. ACS Nano 2013, 7, 47154732. [PubMed: 23721608] (c)Robertson EJ; Battigelli A; Proulx C; Mannige RV; Haxton TK; Yun L; Whitelam S; Zuckermann RN Design, Synthesis, Assembly, and Engineering of Peptoid Nanosheets. Acc. Chem. Res 2016, 49, 379-389. [PubMed: 26741294]

(2) (a). Simon RJ; Kania RS; Zuckermann RN; Huebner VD; Jewell DA; Banville S; Ng S; Wang L; Rosenberg S; Marlowe CK Peptoids: a modular approach to drug discovery. Proc. Natl. Acad. Sci U.S.A 1992, 89, 9367-9371. [PubMed: 1409642] (b)Goodman CM; Choi S; Shandler S; DeGrado WF Foldamers as versatile frameworks for the design and evolution of function. Nat. Chem. Biol 2007, 3, 252-262. [PubMed: 17438550] (c)Horne WS; Gellman SH Foldamers with Heterogeneous Backbones. Acc. Chem. Res 2008, 41, 1399-1408. [PubMed: 18590282] (d)Pelay-Gimeno M; Glas A; Koch O; Grossmann TN Structure-Based Design of Inhibitors of Protein-Protein Interactions: Mimicking Peptide Binding Epitopes. Angew. Chem., Int. Ed 2015, 54, 8896-8927.(e)Groß A; Hashimoto C; Sticht H; Eichler J Synthetic Peptides as Protein Mimics. Front. Bioeng. Biotech 2016, 3, No. 211.(f)Lenci E; Trabocchi A Peptidomimetic toolbox for drug discovery. Chem. Soc. Rev 2020, 49, 3262-3277. [PubMed: 32255135]

(3) (a). Robinson JA $\beta$-Hairpin Peptidomimetics: Design, Structures and Biological Activities. Acc. Chem. Res 2008, 41, 1278-1288. [PubMed: 18412373] (b)Robinson JA; DeMarco S; Gombert F; Moehle K; Obrecht D The design, structures and therapeutic potential of protein epitope mimetics. Drug Discovery Today 2008, 13, 944-951. [PubMed: 18725320] (c)Obrecht D; Chevalier E; Moehle K; Robinson JA $\beta$-Hairpin protein epitope mimetic technology in drug discovery. Drug Discovery Today: Technol 2012, 9, e63-e69.(d)Zerbe K; Moehle K; Robinson JA Protein Epitope Mimetics: From New Antibiotics to Supramolecular Synthetic Vaccines. Acc. Chem. Res 2017, 50, 1323-1331. [PubMed: 28570824]

(4) (a). Schneider JP; Kelly JW Templates That Induce alpha-Helical, beta-Sheet, and Loop Conformations. Chem. Rev 1995, 95, 2169-2187.(b)Merritt HI; Sawyer N; Arora PS Bent into shape: Folded peptides to mimic protein structure and modulate protein function. Peptide Sci. 2020, 112, No. e24145.

(5). Gunasekaran K; Ramakrishnan C; Balaram P $\beta$-hairpins in proteins revisited: lessons for de novo design. Protein Eng. Des. Sel 1997, 10, 1131-1141.

(6). Del Valle JR Heterocyclic Extended Peptide Surrogates for $\beta$-Strand Stabilization. In Peptidomimetics II; Lubell W, Ed.; Springer International Publishing: Cham, 2017; pp 25-49.

(7) (a). Martin ACR; Toda K; Stirk HJ; Thornton JM Long loops in proteins. Protein Eng. Des. Sel 1995, 8, 1093-1101.(b)Donate LE; Rufino SD; Canard LHJ; Blundell TL Conformational analysis and clustering of short and medium size loops connecting regular secondary structures: A database for modeling and prediction. Protein Sci. 1996, 5, 2600-2616. [PubMed: 8976569] (c)Siegert TR; Bird MJ; Makwana KM; Kritzer JA Analysis of Loops that Mediate ProteinProtein Interactions and Translation into Submicromolar Inhibitors. J. Am. Chem. Soc 2016, 138, 12876-12884. [PubMed: 27611902] (d)Marcos E; Chidyausiku TM; McShan AC; Evangelidis T; Nerli S; Carter L; Nivón LG; Davis A; Oberdorfer G; Tripsianes K; Sgourakis NG; Baker D De novo design of a non-local $\beta$-sheet protein with high stability and accuracy. Nat. Struct. Mol. Biol 2018, 25, 1028-1034. [PubMed: 30374087]

J Org Chem. Author manuscript; available in PMC 2021 November 09. 
(8) (a). Espinosa JF; Muoz V; Gellman SH Interplay Between Hydrophobic Cluster and Loop Propensity in $\beta$-Hairpin Formation. J. Mol. Biol 2001, 306, 397-402. [PubMed: 11178900] (b)Verma A; Wenzel W Predictive and Reproducible de Novo All-Atom Folding of a $\beta$-Hairpin Loop in an Improved Free-Energy Forcefield. J. Phys.: Condens. Matter 2007, 19, No. 285213. (c)Anderson JM; Jurban B; Huggins KNL; Shcherbakov AA; Shu I; Kier B; Andersen NH Nascent Hairpins in Proteins: Identifying Turn Loci and Quantitating Turn Contributions to Hairpin Stability. Biochemistry 2016, 55, 5537-5553. [PubMed: 27601214] (d)Sawyer N; Arora PS Hydrogen Bond Surrogate Stabilization of $\beta$-Hairpins. ACS Chem. Biol 2018, 13, $2027-$ 2032. [PubMed: 30005156]

(9) (a). Smith CK; Withka JM; Regan L A Thermodynamic Scale for the beta-Sheet Forming Tendencies of the Amino Acids. Biochemistry 1994, 33, 5510-5517. [PubMed: 8180173] (b)Russell SJ; Cochran AG Designing Stable $\beta$-Hairpins: Energetic Contributions from CrossStrand Residues. J. Am. Chem. Soc 2000, 122, 12600-12601.(c)Syud FA; Stanger HE; Gellman SH Interstrand Side Chain-Side Chain Interactions in a Designed $\beta$-Hairpin: Significance of Both Lateral and Diagonal Pairings. J. Am. Chem. Soc 2001, 123, 8667-8677. [PubMed: 11535071] (d)Nowick JS Exploring $\beta$-Sheet Structure and Interactions with Chemical Model Systems. Acc. Chem. Res 2008, 41, 1319-1330. [PubMed: 18798654]

(10) (a). Jäger M; Nguyen H; Crane JC; Kelly JW; Gruebele M The folding mechanism of a $\beta$-sheet: The WW domain. J. Mol. Biol 2001, 311, 373-393. [PubMed: 11478867] (b)Jäger M; Zhang Y; Bieschke J; Nguyen H; Dendle M; Bowman ME; Noel JP; Gruebele M; Kelly JW Structurefunction-folding relationship in a WW domain. Proc. Natl. Acad. Sci. U.S.A 2006, 103, 1064810653. [PubMed: 16807295] (c)Cochran AG; Tong RT; Starovasnik MA; Park EJ; McDowell RS; Theaker JE; Skelton NJ A Minimal Peptide Scaffold for $\beta$-Turn Display: Optimizing a Strand Position in Disulfide-Cyclized $\beta$-Hairpins. J. Am. Chem. Soc 2001, 123, 625-632. [PubMed: 11456574]

(11) (a). Hutchinson EG; Sessions RB; Thornton JM; Woolfson DN Determinants of strand register in antiparallel $\beta$-sheets of proteins. Protein Sci. 1998, 7, 2287-2300. [PubMed: 9827995] (b)Merkel JS; Sturtevant JM; Regan L Sidechain interactions in parallel $\beta$ sheets: the energetics of crossstrand pairings. Structure 1999, 7, 1333-1343. [PubMed: 10574793] (c)Dyer RB; Maness SJ; Peterson ES; Franzen S; Fesinmeyer RM; Andersen NH The Mechanism of $\beta$-Hairpin Formation. Biochemistry 2004, 43, 11560-11566. [PubMed: 15350142]

(12). Sibanda BL; Blundell TL; Thornton JM Conformation of $\beta$-hairpins in protein structures: A systematic classification with applications to modelling by homology, electron density fitting and protein engineering. J. Mol. Biol 1989, 206, 759-777. [PubMed: 2500530]

(13) (a). Gellman SH Minimal model systems for $\beta$-sheet secondary structure in proteins. Curr. Opin. Chem. Biol 1998, 2, 717-725. [PubMed: 9914187] (b)Lacroix E; Kortemme T; De la Paz ML; Serrano L The design of linear peptides that fold as monomeric $\beta$-sheet structures. Curr. Opin. Struct. Biol 1999, 9, 487-493. [PubMed: 10449370] (c)Searle MS; Ciani B Design of $\beta$-sheet systems for understanding the thermodynamics and kinetics of protein folding. Curr. Opin. Struct. Biol 2004, 14, 458-464. [PubMed: 15313241] (d)Hughes RM; Waters ML Model systems for $\beta$-hairpins and $\beta$-sheets. Curr. Opin. Struct. Biol 2006, 16, 514-524. [PubMed: 16837192]

(14) (a). Blanco FJ; Rivas G; Serrano L A short linear peptide that folds into a native stable $\beta$-hairpin in aqueous solution. Nat. Struct. Mol. Biol 1994, 1, 584-590.(b)Anderson JM; Andersen NH A pH Switch for $\beta$-Sheet Protein Folding. Angew. Chem., Int. Ed 2017, 56, 7074-7077.(c)Fischer S; Lamping M; Gold M; Röttger Y; Brödje D; Dodel R; Frantz R; Mraheil MA; Chakraborty T; Geyer A Synthesis of a biological active $\beta$-hairpin peptide by addition of two structural motifs. Bioorg. Med. Chem 2017, 25, 603-608. [PubMed: 27887962] (d)For a recent review, see Morales P; Jiménez MA Design and structural characterisation of monomeric water-soluble $a$-helix and $\beta$-hairpin peptides: State-of-the-art. Arch. Biochem. Biophys 2019, 661, 149-167. [PubMed: 30468710]

(15) (a). Ramírez-Alvarado M; Blanco FJ; Serrano L De novo design and structural analysis of a model $\beta$-hairpin peptide system. Nat. Struct. Mol. Biol 1996, 3, 604-612.(b)Kaul R; Angeles AR; Jaeger M; Powers ET; Kelly JW Incorporating $\beta$-Turns and a Turn Mimetic out of Context in Loop 1 of the WW Domain Affords Cooperatively Folded $\beta$-Sheets. J. Am. Chem. Soc 2001, 123, 5206-5212. [PubMed: 11457382] 
(16) (a). Kier BL; Shu I; Eidenschink LA; Andersen NH Stabilizing capping motif for $\beta$-hairpins and sheets. Proc. Natl. Acad. Sci. U.S.A 2010, 107, 10466-10471. [PubMed: 20484672] (b)Anderson JM; Kier BL; Shcherbakov AA; Andersen NH An improved capping unit for stabilizing the ends of associated $\beta$-strands. FEBS Lett. 2014, 588, 4749-4753. [PubMed: 25451230] (c)Anderson JM; Shcherbakov AA; Kier BL; Kellock J; Shu I; Byrne AL; Eidenschink LA; Andersen NH Optimization of a $\beta$-sheet-cap for long loop closure. Biopolymers 2017, 107, No. e22995.

(17) (a). Viguera A-R; Serrano L Loop length, intramolecular diffusion and protein folding. Nat. Struct. Mol. Biol 1997, 4, 939-946.(b)Nagi AD; Regan L An inverse correlation between loop length and stability in a four-helix-bundle protein. Fold. Des 1997, 2, 67-75. [PubMed: 9080200] (c)Krieger F; Möglich A; Kiefhaber T Effect of Proline and Glycine Residues on Dynamics and Barriers of Loop Formation in Polypeptide Chains. J. Am. Chem. Soc 2005, 127, 3346-3352. [PubMed: 15755151] (d)Tzul FO; Bowler BE Importance of Contact Persistence in Denatured State Loop Formation: Kinetic Insights into Sequence Effects on Nucleation Early in Folding. J. Mol. Biol 2009, 390, 124-134. [PubMed: 19426739]

(18). Stanger HE; Syud FA; Espinosa JF; Giriat I; Muir T; Gellman SH Length-dependent stability and strand length limits in antiparallel $\beta$-sheet secondary structure. Proc. Natl. Acad. Sci. U.S.A 2001, 98, 12015-12020. [PubMed: 11593011]

(19) (a). Marsault E; Peterson ML Macrocycles are great cycles: applications, opportunities, and challenges of synthetic macrocycles in drug discovery. J. Med. Chem 2011, 54, 1961-2004. [PubMed: 21381769] (b)Giordanetto F; Kihlberg J Macrocyclic Drugs and Clinical Candidates: What Can Medicinal Chemists Learn from Their Properties? J. Med. Chem 2014, 57, 278-295. [PubMed: 24044773] (c)Naylor MR; Bockus AT; Blanco M-J; Lokey RS Cyclic peptide natural products chart the frontier of oral bioavailability in the pursuit of undruggable targets. Curr. Opin. Chem. Biol 2017, 38, 141-147. [PubMed: 28570865] (d)Vinogradov AA; Yin Y; Suga H Macrocyclic Peptides as Drug Candidates: Recent Progress and Remaining Challenges. J. Am. Chem. Soc 2019, 141, 4167-4181. [PubMed: 30768253]

(20). Richaud A; Zhao G; Roche SP; Hobloss S Folding in Place: Design of $\beta$-Strap Motifs to Stabilize the Folding of Hairpins with Long Loops, 2021. 10.26434/chemrxiv.12912452.v2.

(21) (a). Maute RL; Gordon SR; Mayer AT; McCracken MN; Natarajan A; Ring NG; Kimura R; Tsai JM; Manglik A; Kruse AC; Gambhir SS; Weissman IL; Ring AM Engineering high-affinity PD-1 variants for optimized immunotherapy and immuno-PET imaging. Proc. Natl. Acad. Sci. U.S.A 2015, 112, E6506-E6514. [PubMed: 26604307] (b)Horita S; Nomura Y; Sato Y; Shimamura T; Iwata S; Nomura N High-resolution crystal structure of the therapeutic antibody pembrolizumab bound to the human PD-1. Sci. Rep 2016, 6, No. 35297. [PubMed: 27734966]

(22) (a). Zondlo NJ Non-covalent interactions: Fold globally, bond locally. Nat. Chem. Biol 2010, 6, 567-568. [PubMed: 20644541] (b)Knowles RR; Jacobsen EN Attractive noncovalent interactions in asymmetric catalysis: Links between enzymes and small molecule catalysts. Proc. Natl. Acad. Sci. U.S.A 2010, 107, 20678-20685. [PubMed: 20956302] (c)Neel AJ; Hilton MJ; Sigman MS; Toste FD Exploiting non-covalent $\pi$ interactions for catalyst design. Nature 2017, 543, 637-646. [PubMed: 28358089] (d)Newberry RW; Raines RT Secondary Forces in Protein Folding. ACS Chem. Biol 2019, 14, 1677-1686. [PubMed: 31243961]

(23). Fesinmeyer RM; Hudson FM; Andersen NH Enhanced Hairpin Stability through Loop Design: The Case of the Protein G B1 Domain Hairpin. J. Am. Chem. Soc 2004, 126, 7238-7243. [PubMed: 15186161]

(24). Kier BL; Andersen NH Probing the Lower Size Limit for Protein-Like Fold Stability: TenResidue Microproteins With Specific, Rigid Structures in Water. J. Am. Chem. Soc 2008, 130, 14675-14683. [PubMed: 18842046]

(25) (a). Russell SJ; Cochran AG Designing Stable $\beta$-Hairpins: Energetic Contributions from CrossStrand Residues. J. Am. Chem. Soc 2000, 122, 12600-12601.(b)Cochran AG; Skelton NJ; Starovasnik MA Tryptophan zippers: stable, monomeric $\beta$-hairpins. Proc. Natl. Acad. Sci. U.S.A 2001, 98, 5578-5583. [PubMed: 11331745] (c)Russell SJ; Blandl T; Skelton NJ; Cochran AG Stability of Cyclic $\beta$-Hairpins: Asymmetric Contributions from Side Chains of a HydrogenBonded Cross-Strand Residue Pair. J. Am. Chem. Soc 2003, 125, 388-395. [PubMed: 12517150] (d)Cochran AG; Starovasnik MA; Skelton N Hairpin Peptides with a Novel Structural Motif and Methods Relating Thereto. U.S. Patent US20030175799A12003. 
(26). Andersen NH; Olsen KA; Fesinmeyer RM; Tan X; Hudson FM; Eidenschink LA; Farazi SR Minimization and Optimization of Designed $\beta$-Hairpin Folds. J. Am. Chem. Soc 2006, 128, 6101-6110. [PubMed: 16669679]

(27). Lengyel GA; Horne WS Design Strategies for the Sequence-Based Mimicry of Side-Chain Display in Protein $\beta$-Sheets by a/a-Peptides. J. Am. Chem. Soc 2012, 134, 15906-15913. [PubMed: 22946450]

(28). Giraud M; Cavelier F; Martinez J A side-reaction in the SPPS of Trp-containing peptides. J. Pept. Sci 1999, 5, 457-461. [PubMed: 10580644]

(29). Greenfield NJ Using circular dichroism collected as a function of temperature to determine the thermodynamics of protein unfolding and binding interactions. Nat. Protoc 2006, 1, 2527-2535. [PubMed: 17406506] Protocol III described in the Supporting Information associated with this manuscript $\left(\Delta C_{\mathrm{p}} \neq 0\right)$ was used to generate the best-fitted melts reported herein

(30) (a). Eidenschink L; Kier BL; Huggins KNL; Andersen NH Very short peptides with stable folds: Building on the interrelationship of Trp/Trp, Trp/cation, and Trp/backbone-amide interaction geometries. Proteins 2009, 75, 308-322. [PubMed: 18831035] (b)Anderson JM; Kier BL; Jurban B; Byrne A; Shu I; Eidenschink LA; Shcherbakov AA; Hudson M; Fesinmeyer RM; Andersen $\mathrm{NH}$ Aryl-aryl interactions in designed peptide folds: Spectroscopic characteristics and optimal placement for structure stabilization. Biopolymers 2016, 105, 337-356. [PubMed: 26850220]

(31) (a). Huang R; Wu L; McElheny D; Bouř P; Roy A; Keiderling TA Cross-Strand Coupling and Site-Specific Unfolding Thermodynamics of a Trpzip $\beta$-Hairpin Peptide Using 13C Isotopic Labeling and IR Spectroscopy. J. Phys. Chem. B 2009, 113, 5661-5674. [PubMed: 19326892] (b)Takekiyo T; Wu L; Yoshimura Y; Shimizu A; Keiderling TA Relationship between Hydrophobic Interactions and Secondary Structure Stability for Trpzip $\beta$-Hairpin Peptides. Biochemistry 2009, 48, 1543-1552. [PubMed: 19173596] (c)Wu L; McElheny D; Takekiyo T; Keiderling TA Geometry and Efficacy of Cross-Strand Trp/Trp, Trp/Tyr, and Tyr/Tyr Aromatic Interaction in a $\beta$-Hairpin Peptide. Biochemistry 2010, 49, 4705-4714. [PubMed: 20423111]

(32) (a). Guvench O; Brooks CL Tryptophan Side Chain Electrostatic Interactions Determine Edgeto-Face vs Parallel-Displaced Tryptophan Side Chain Geometries in the Designed $\beta$-Hairpin “trpzip2". J. Am. Chem. Soc 2005, 127, 4668-4674. [PubMed: 15796532] (b)Wu L; McElheny D; Huang R; Keiderling TA Role of Tryptophan-Tryptophan Interactions in Trpzip $\beta$-Hairpin Formation, Structure, and Stability. Biochemistry 2009, 48, 10362-10371. [PubMed: 19788311]

(33) (a). Jennings WB; Farrell BM; Malone JF Attractive Intramolecular Edge-to-Face Aromatic Interactions in Flexible Organic Molecules. Acc. Chem. Res 2001, 34, 885-894. [PubMed: 11714260] (b)Carver FJ; Hunter CA; Jones PS; Livingstone DJ; McCabe JF; Seward EM; Tiger P; Spey SE Quantitative Measurements of Edge-to-Face Aromatic Interactions by Using Chemical Double-Mutant Cycles. Chem. - Eur. J 2001, 7, 4854-4862. [PubMed: 11763454] (c)Wheeler SE; Houk KN Origin of substituent effects in edge-to-face aryl-aryl interactions. Mol. Phys 2009, 107, 749-760. [PubMed: 20046948] (d)For a recent review, see Nishio M; Umezawa Y; Fantini J; Weiss MS; Chakrabarti P CH- $\pi$ hydrogen bonds in biological macromolecules. Phys. Chem. Chem. Phys 2014, 16, 12648-12683. [PubMed: 24836323]

(34). See Supporting Information for complete experimental details.

(35). By using $[\theta]_{\mathrm{RC}(95)}$ measured at $95^{\circ} \mathrm{C}$ as unfolded reference, the value of $[\theta]_{\mathrm{U}}$ for each peptide must be approaching the origin at elevated temperatures, $[\theta]_{\mathrm{U}}=[\theta(\mathrm{T})]_{228}-[\theta]_{\mathrm{RC}(95)}=0^{\circ}$, thus defining the experimental unfolded baseline by extrapolation.

(36) (a). Privalov PL Stability of Proteins Small Globular Proteins. In Advances in Protein Chemistry; Anfinsen CB; Edsall JT; Richards FM, Eds.; Academic Press, 1979; Vol. 33, pp 167-241. [PubMed: 44431] (b)Prabhu NV; Sharp KA Heat capacity in proteins. Annu. Rev. Phys. Chem 2005, 56, 521-548. [PubMed: 15796710]

(37). The temperatures $T_{\mathrm{m}}$ of melting-transition were determined from the best-fitted curves of $[\theta(\mathrm{T})]_{228}$ to the Gibbs-Helmholtz equation, and from the first-derivative method of the raw curve $[\theta(\mathrm{T})]_{228}$ for comparison; see Table S1.

(38) (a). Meuzelaar H; Vreede J; Woutersen S Influence of Glu/Arg, Asp/Arg, and Glu/Lys Salt Bridges on $a$-Helical Stability and Folding Kinetics. Biophys. J 2016, 110, 2328-2341. [PubMed: 27276251] (b)Wolny M; Batchelor M; Bartlett GJ; Baker EG; Kurzawa M; Knight PJ; Dougan L; Woolfson DN; Paci E; Peckham M Characterization of long and stable de novo 
single alpha-helix domains provides novel insight into their stability. Sci. Rep 2017, 7, No. 44341. [PubMed: 28287151]

(39) (a). Ciani B; Jourdan M; Searle MS Stabilization of $\beta$-Hairpin Peptides by Salt Bridges: Role of Preorganization in the Energetic Contribution of Weak Interactions. J. Am. Chem. Soc 2003, 125, 9038-9047. [PubMed: 15369359] (b)Kiehna SE; Waters ML Sequence dependence of $\beta$-hairpin structure: Comparison of a salt bridge and an aromatic interaction. Protein Sci. 2003, 12, 26572667. [PubMed: 14627727] (c)Scian M; Shu I; Olsen KA; Hassam K; Andersen NH Mutational Effects on the Folding Dynamics of a Minimized Hairpin. Biochemistry 2013, 52, 2556-2564. [PubMed: 23521619] (d)Smith MS; Billings WM; Whitby FG; Miller MB; Price JL Enhancing a long-range salt bridge with intermediate aromatic and nonpolar amino acids. Org. Biomol. Chem 2017, 15, 5882-5886. [PubMed: 28678274] (e)Bureau HR; Quirk S; Hernandez R The relative stability of trpzip1 and its mutants determined by computation and experiment. RSC Adv. 2020, $10,6520-6535$.

(40). For recent reviews covering protein thermal stability, see (a) Karshikoff A; Nilsson L; Ladenstein R Rigidity versus flexibility: the dilemma of understanding protein thermal stability. FEBS J. 2015, 282, 3899-3917. [PubMed: 26074325] (b)Pucci F; Rooman M Physical and molecular bases of protein thermal stability and cold adaptation. Curr. Opin. Struct. Biol 2017, 42, 117-128. [PubMed: 28040640] (c)Kazlauskas R Engineering more stable proteins. Chem. Soc. Rev 2018, 47, 9026-9045. [PubMed: 30306986]

(41) (a). Rees DC; Robertson AD Some thermodynamic implications for the thermostability of proteins. Protein Sci. 2001, 10, 1187-1194. [PubMed: 11369857] (b)Kumar S; Tsai C-J; Nussinov R Thermodynamic Differences among Homologous Thermophilic and Mesophilic Proteins. Biochemistry 2001, 40, 14152-14165. [PubMed: 11714268] (c)Kumar S; Tsai C-J; Nussinov R Maximal Stabilities of Reversible Two-State Proteins. Biochemistry 2002, 41, 53595374. [PubMed: 11969396] (d)Pica A; Graziano G Shedding light on the extra thermal stability of thermophilic proteins. Biopolymers 2016, 105, 856-863. [PubMed: 27449333]

(42) (a). Pace CN; Laurents DV A new method for determining the heat capacity change for protein folding. Biochemistry 1989, 28, 2520-2525. [PubMed: 2499351] (b)Spolar RS; Ha JH; Record MT Hydrophobic effect in protein folding and other noncovalent processes involving proteins. Proc. Natl. Acad. Sci. U.S.A 1989, 86, 8382-8385. [PubMed: 2813394] (c)Oliveberg M; Tan YJ; Fersht AR Negative activation enthalpies in the kinetics of protein folding. Proc. Natl. Acad. Sci. U.S.A 1995, 92, 8926-8929. [PubMed: 7568045]

(43) (a). Griffiths-Jones SR; Maynard AJ; Searle MS Dissecting the Stability of a $\beta$-Hairpin Peptide that Folds in Water: NMR and Molecular Dynamics Analysis of the $\beta$-Turn and $\beta$-Strand Contributions to Folding. J. Mol. Biol 1999, 292, 1051-1069. [PubMed: 10512702] (b)Santiveri CM; Santoro J; Rico M; Jiménez MA Thermodynamic Analysis of $\beta$-Hairpin-Forming Peptides from the Thermal Dependence of ${ }^{1}$ H NMR Chemical Shifts. J. Am. Chem. Soc 2002, 124 , 14903-14909. [PubMed: 12475331]

(44) (a). CSD defined as experimental $\delta$ value - computed random coil $\delta$ value; computed random coil chemical shifts prediction including correction factors developed by Maltsev and Poulsen were used: https://spin.niddk.nih.gov/bax/nmrserver/Poulsen_rc_CS/.For details on prediction calculations, see. (b) Schwarzinger S; Kroon GJA; Foss TR; Chung J; Wright PE; Dyson HJ Sequence-Dependent Correction of Random Coil NMR Chemical Shifts. J. Am. Chem. Soc 2001, 123, 2970-2978. [PubMed: 11457007] (c)Kjaergaard M; Poulsen FM Sequence correction of random coil chemical shifts: correlation between neighbor correction factors and changes in the Ramachandran distribution. J. Biomol NMR 2011, 50, 157-165. [PubMed: 21604143]

(45) (a). Wishart DS; Sykes BD; Richards FM The chemical shift index: a fast and simple method for the assignment of protein secondary structure through NMR spectroscopy. Biochemistry 1992, 31, 1647-1651. [PubMed: 1737021] (b)Andersen NH; Dyer RB; Fesinmeyer RM; Gai F; Liu Z; Neidigh JW; Tong H Effect of Hexafluoroisopropanol on the Thermodynamics of Peptide Secondary Structure Formation. J. Am. Chem. Soc, 1999, 121, 9879-9880.(c)Fesinmeyer RM; Hudson FM; Olsen KA; White GWN; Euser A; Andersen NH Chemical Shifts Provide Fold Populations and Register of $\beta$ Hairpins and $\beta$ Sheets. J. Biomol. NMR 2005, 33, 213-231. [PubMed: 16341751] 
(46). Aravinda S; Shamala N; Das C; Sriranjini A; Karle IL; Balaram P Aromatic-Aromatic Interactions in Crystal Structures of Helical Peptide Scaffolds Containing Projecting Phenylalanine Residues. J. Am. Chem. Soc 2003, 125, 5308-5315. [PubMed: 12720442]

(47). Tatko CD; Waters ML Selective Aromatic Interactions in $\beta$-Hairpin Peptides. J. Am. Chem. Soc 2002, 124, 9372-9373. [PubMed: 12167022]

(48) (a). Lengyel GA; Eddinger GA; Horne WS Introduction of Cyclically Constrained $\gamma$-Residues Stabilizes an $a$-Peptide Hairpin in Aqueous Solution. Org. Lett 2013, 15, 944-947. [PubMed: 23390979] (b)Lengyel GA; Reinert ZE; Griffith BD; Horne WS Comparison of backbone modification in protein $\beta$-sheets by $a \rightarrow \gamma$ residue replacement and $a$-residue methylation. Org. Biomol. Chem 2014, 12, 5375-5381. [PubMed: 24909436] (c)Sarnowski MP; Pedretty KP; Giddings N; Woodcock HL; Del Valle JR Synthesis and $\beta$-sheet propensity of constrained $\mathrm{N}$-amino peptides. Bioorg. Med. Chem 2018, 26, 1162-1166. [PubMed: 28882503]

(49). As for the unfolded controls, synthetic random coils SI-RC1-4 displayed a $\Delta \delta \mathrm{H}_{a / a} \mathrm{G}(\mathrm{L} 4)$ of 0 ppm throughout our study.

(50). See the Supporting Information of ref 26, page S3 for a comparative table of tryptophan chemical shifts from EtF W/W sidechain interactions found in Trpzip4, HP5W4, HP7, and the tryptophan chemical shift values for the unfolded random coil reference.

(51). Ladurner AG; Fersht AR Glutamine, alanine or glycine repeats inserted into the loop of a protein have minimal effects on stability and folding rates. J. Mol. Biol 1997, 273, 330-337. [PubMed: 9367765]

(52) (a). Hill TA; Shepherd NE; Diness F; Fairlie DP Constraining Cyclic Peptides To Mimic Protein Structure Motifs. Angew. Chem., Int. Ed 2014, 53, 13020-13041.(b)Dougherty PG; Qian Z; Pei D Macrocycles as protein-protein interaction inhibitors. Biochem. J 2017, 474, 1109-1125. [PubMed: 28298556]

(53). Gavenonis J; Sheneman BA; Siegert TR; Eshelman MR; Kritzer JA Comprehensive analysis of loops at protein-protein interfaces for macrocycle design. Nat. Chem. Biol 2014, 10, 716-722. [PubMed: 25038791]

(54). Menges F Spectragryph - Optical Spectroscopy Software, Version 1.2.13. http:// www.effemm2.de/spectragryph/, 2019. 
A. [4:6]-Hairpins

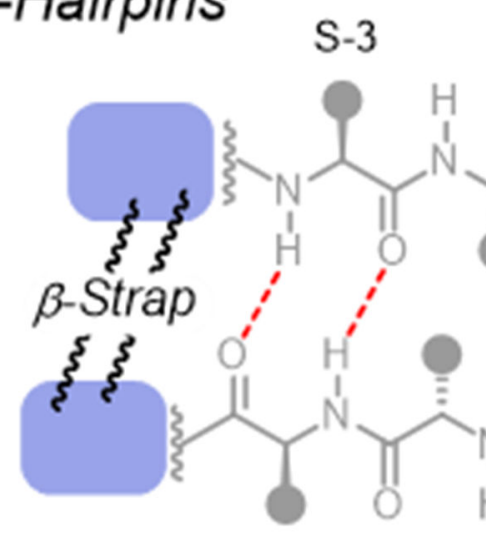

$\mathrm{S}-1$

L1

$\mathrm{S}-1$
Asn/Asp

L2

Ala/Ala
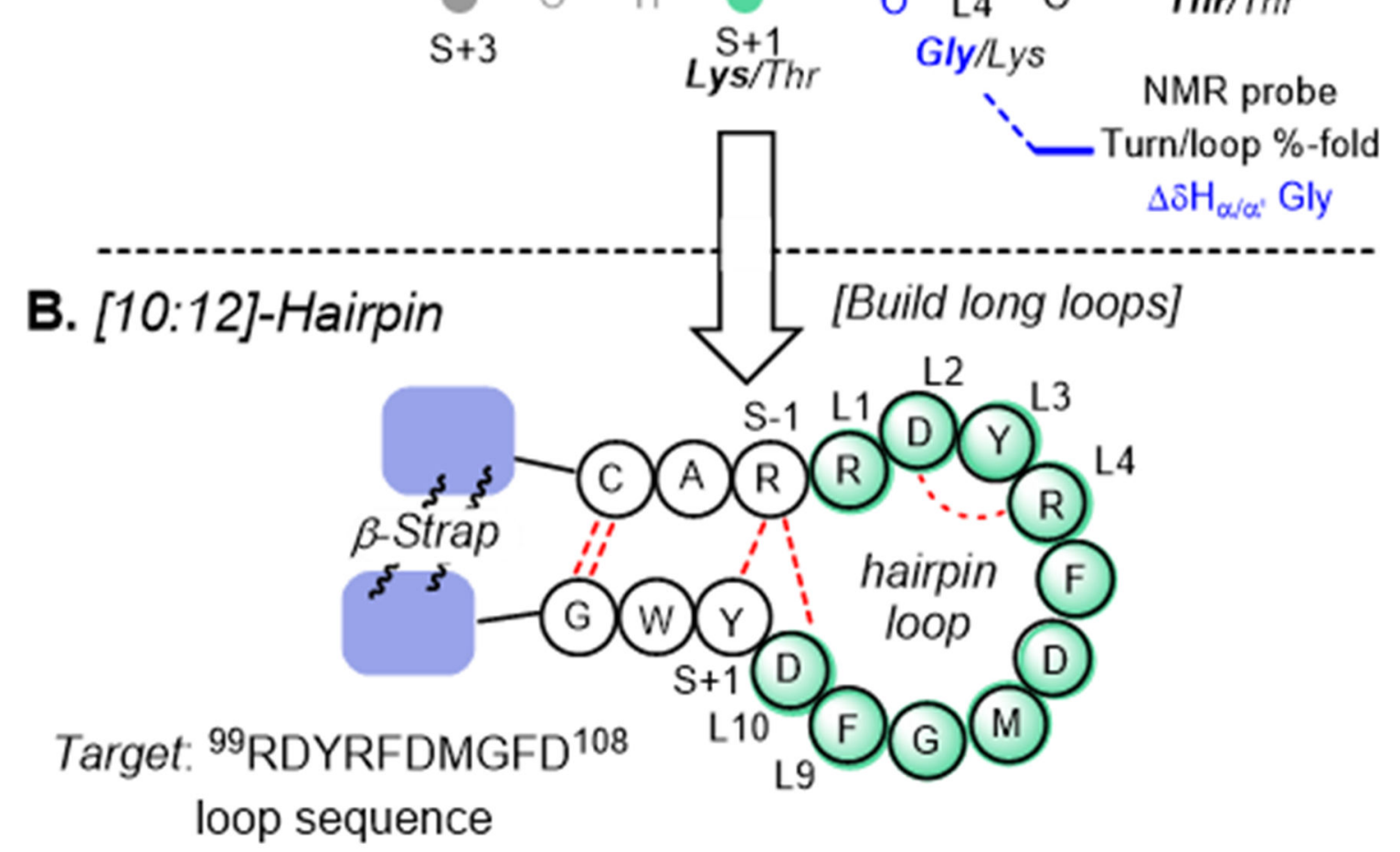

Figure 1.

(A) Strand alignment and H-bonding pattern in folded [4:6]-hairpins based on DDATKT and NPATGK sequences. (B) Schematic representation and nomenclature of a [10:12]-hairpin displaying the 10-mer CDR-H3 loop excised from the pembrolizumab antibody target. 
$\square$ Previous approach. Long $\beta$-strand and $\beta$-cap stabilizing motifs $\beta$-cap $\beta$-strand 000 Typical length (cap + strand) $\geq 10-12$ residues Restricted by loop sequence and length

This work. Minimalist $\beta$-strap $=\beta$-strand $+\beta$-cap

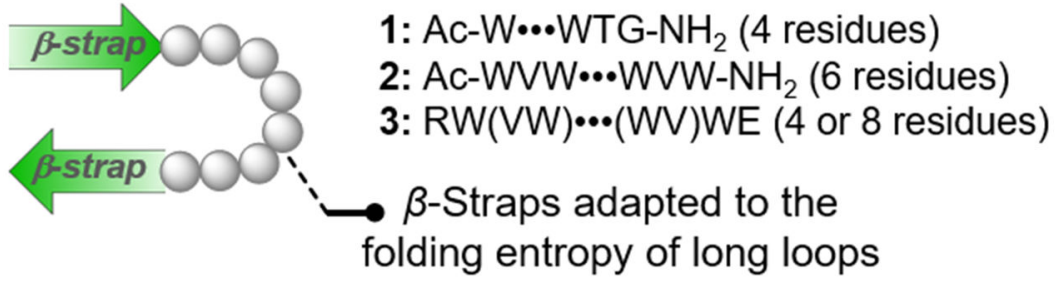

Figure 2.

Design of short stabilizing $\beta$-strap motifs for the hairpin fold. 


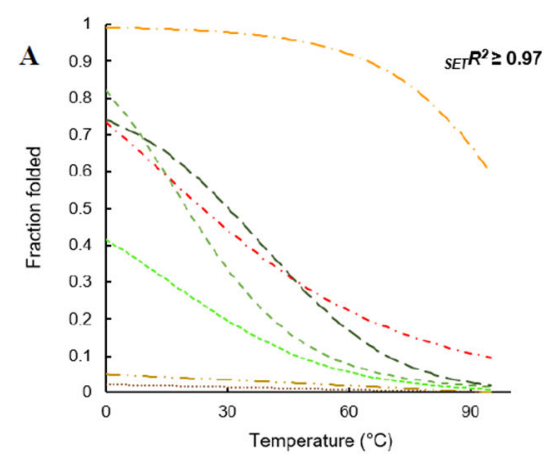

B

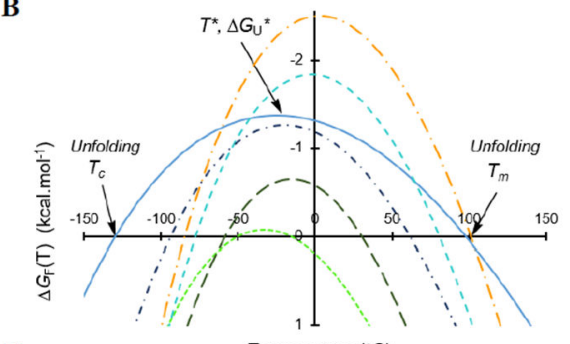

C

\begin{tabular}{|c|c|c|c|c|c|c|c|c|}
\hline Hairpins & $\Delta G_{F}{ }^{\circ}$ & $\Delta H_{F}^{\circ}$ & & $-\mathrm{T} \Delta S_{F}^{\circ}$ & $\Delta C_{p F}{ }^{o}$ & $T^{*}\left({ }^{\circ} \mathrm{C}\right)$ & $\Delta G_{F}^{*}$ & $\Delta \Delta H_{F}{ }^{*}$ \\
\hline $1 \mathrm{a}$ & $0.71 \pm 0.02$ & $-7.13 \pm 0.36$ & 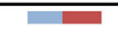 & $7.84 \pm 0.38$ & $-122 \pm 30$ & -33 & $-0.08 \pm 0.02$ & 0 \\
\hline 1b & $0.20 \pm 0.02$ & $-12.05 \pm 0.51$ & 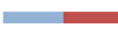 & $12.25 \pm 0.51$ & $\sim 0$ & - & - & - \\
\hline 1c & $-0.14 \pm 0.01$ & $-7.46 \pm 0.02$ & $\square$ & $7.32 \pm 0.02$ & $-170 \pm 1$ & -15 & $-0.65 \pm 0.01$ & -0.57 \\
\hline $2 a$ & $-2.36 \pm 0.05$ & $-5.99 \pm 0.75$ & = & $3.62 \pm 0.71$ & $-159 \pm 17$ & 3 & $-2.50 \pm 0.05$ & -2.42 \\
\hline $2 \mathrm{~b}$ & $0.02 \pm 0.01$ & $-6.84 \pm 0.14$ & $=$ & $6.87 \pm 0.14$ & $\sim 0$ & - & - & - \\
\hline $3 a$ & $-1.13 \pm 0.01$ & $-3.98 \pm 0.05$ & E & $2.85 \pm 0.05$ & $-53 \pm 2$ & -25 & $-1.38 \pm 0.01$ & -1.30 \\
\hline $3 b$ & $-1.63 \pm 0.01$ & $-6.14 \pm 0.12$ & $=$ & $4.51 \pm 0.11$ & $-158 \pm 3$ & -2 & $-1.84 \pm 0.01$ & -1.76 \\
\hline $3 c$ & $-0.87 \pm 0.01$ & $-6.01 \pm 0.11$ & 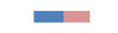 & $5.15 \pm 0.11$ & $-106 \pm 4$ & -20 & $-1.27 \pm 0.01$ & -1.19 \\
\hline $3 d$ & $-0.98 \pm 0.01$ & $-9.27 \pm 0.06$ & 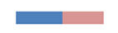 & $8.29 \pm 0.05$ & $-195 \pm 3$ & -15 & $-1.54 \pm 0.01$ & - \\
\hline $3 e$ & $-0.01 \pm 0.01$ & $-4.77 \pm 0.01$ & 口 & $4.76 \pm 0.01$ & $-20 \pm 1$ & -141 & $-1.51 \pm 0.01$ & - \\
\hline $3 f$ & $-0.69 \pm 0.01$ & $-9.67 \pm 0.02$ & 5 & $8.97 \pm 0.02$ & $-43 \pm 1$ & -123 & $-3.18 \pm 0.01$ & - \\
\hline
\end{tabular}

Figure 3.

(A) Thermal denaturation of hairpins 1-3: fraction folded $\left(\chi_{\mathrm{F}}\right)$ curves as a function of temperature $^{\mathrm{a}}$. (B) Thermal stability curves for [4:6]-and [10:12]-hairpins. (C)

Thermodynamic parameters of folding obtained for hairpins 1-3 from a two-state equilibrium model ${ }^{b}$ a Plots of folded fractions were obtained from VT-CD melting curves at $228 \pm 1 \mathrm{~nm}$ for peptides $1-3$ at $22-85 \mu \mathrm{M}$ concentrations (accurately measured by UV-absorbance) in a phosphate buffer (15 mM, pH 6.5). ${ }^{\text {b }}$ Standard thermodynamic parameters calculated at $298 \mathrm{~K}$ with energies reported in $\mathrm{kcal} / \mathrm{mol}$ and heat capacities in cal $\cdot \mathrm{mol}^{-1} \cdot \mathrm{deg}^{-1}$. Thermodynamic data are given \pm standard error calculated from the standard deviations of the best-fitted CD-melt curves of $[\theta(\mathrm{T})]_{228}$ and propagated from the initial uncertainties on measured $\theta$. 

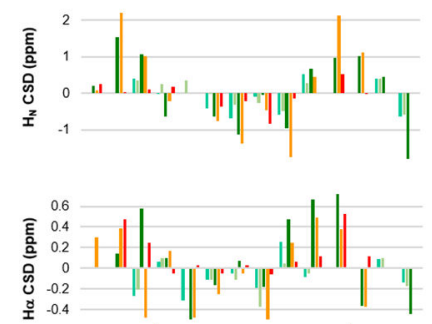

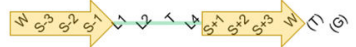

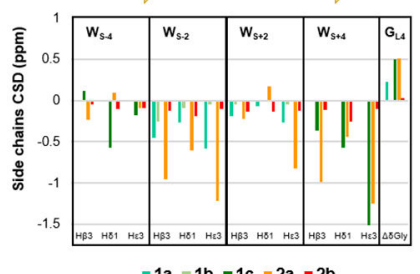

$=1 a=1 b-1 c-2 a=2 b$
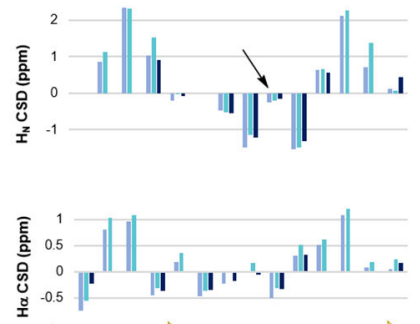

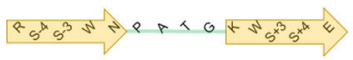

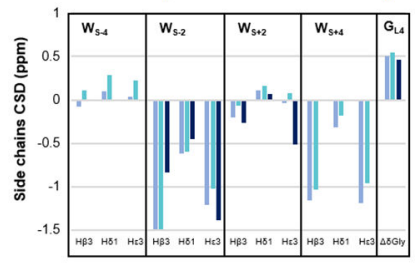

$=3 a=3 b=3 c$

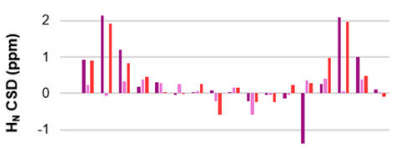

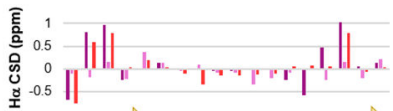

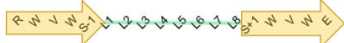

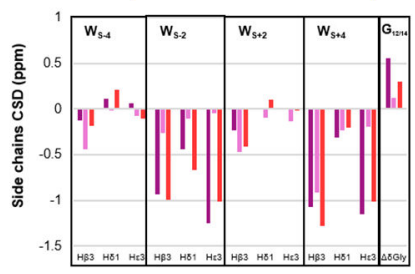

$\because 3 d=3 e=3 f$

Figure 4.

Histograms of backbone $\mathrm{H}_{\mathrm{N}}, \mathrm{H}_{a}$, and Trp side-chain CSD values obtained at $291 \mathrm{~K}$ along the hairpin primary sequences. (A) In the series of strapped $\beta$-hairpins $1 \mathbf{a}-\mathbf{c}$ and $\mathbf{2 a}-\mathbf{b}$. (B) In the series of strapped $\beta$-hairpins 3a-c; the arrow on the histogram points to the unusually deshielded $\mathrm{H}_{\mathrm{N}}(\mathrm{G} 4)$ loop signal, suggesting the presence of an intramolecular H-bond as expected in a [4:6]-hairpin register. (C) In the series of strapped $\beta$-hairpins 3d-e. 

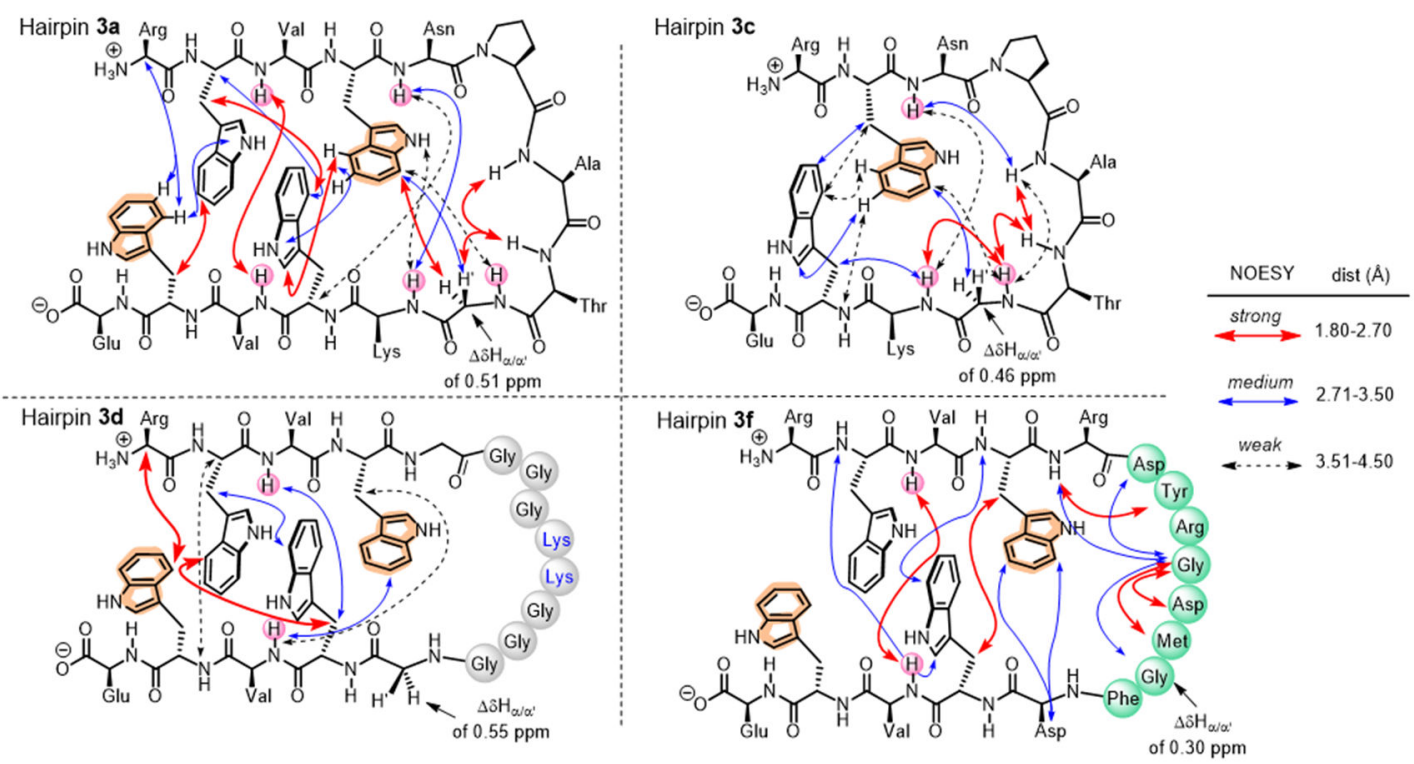

Figure 5.

Structural analysis of hairpins $\mathbf{3 a}, \mathbf{3 c}-\mathbf{d}$, and $\mathbf{3 f}$ by NOESY correlations establishing sidechain to side-chain interactions, the loop orientation, and the hydrogen-bonding register

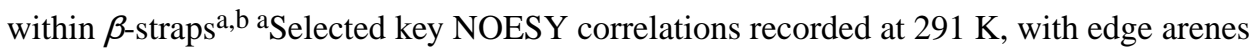
involved in EtF arene-arene interactions highlighted in light orange. ${ }^{\mathrm{b}}$ Hydrogens circled (in pink) in the NOESY diagrams participate in a network of intramolecular hydrogen bonds characteristic of a hairpin register. 

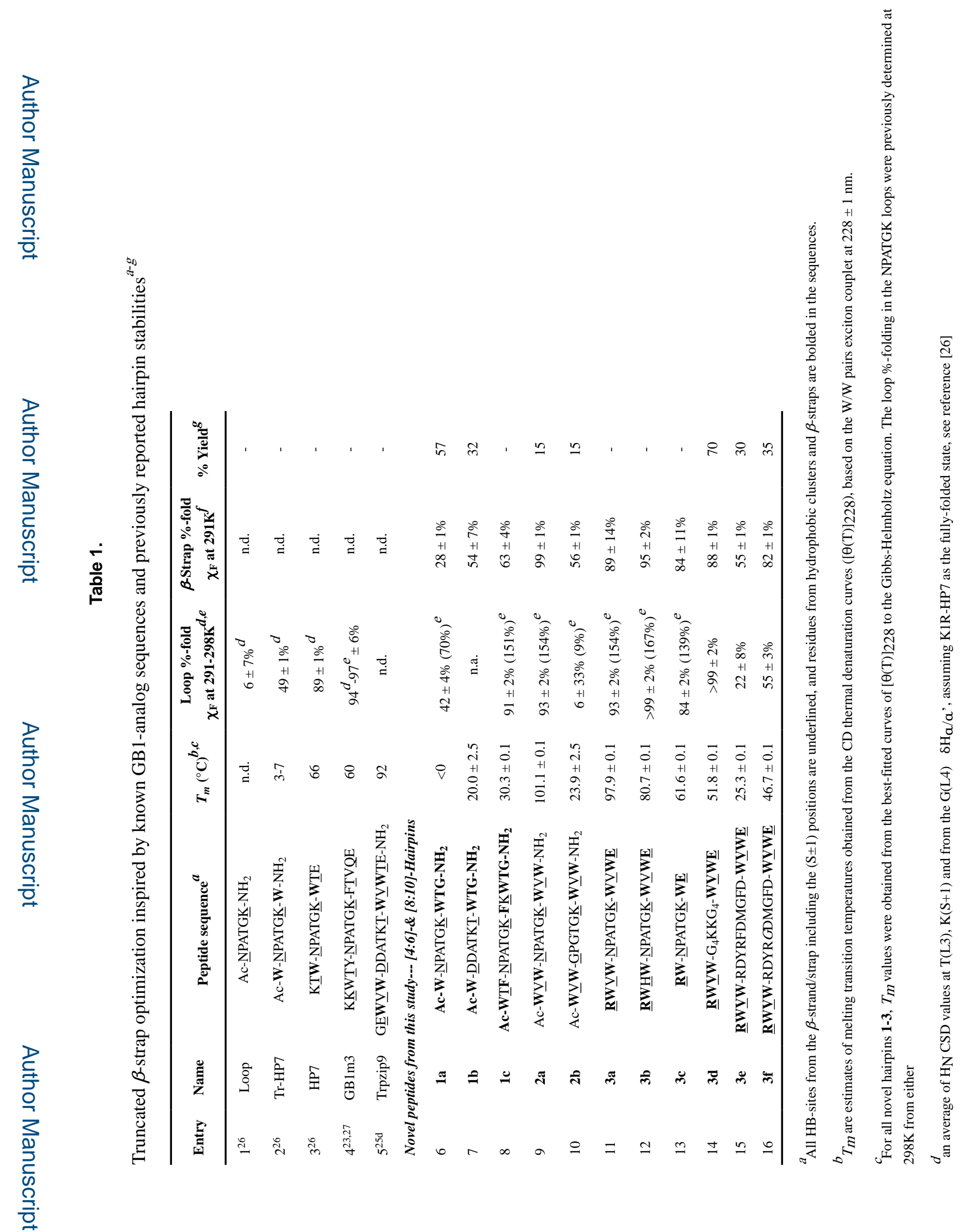

J Org Chem. Author manuscript; available in PMC 2021 November 09. 


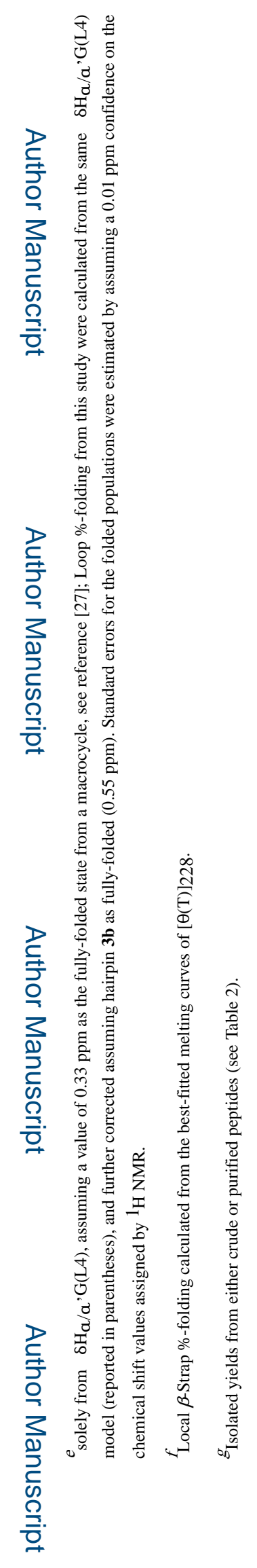

J Org Chem. Author manuscript; available in PMC 2021 November 09. 


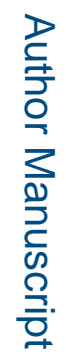

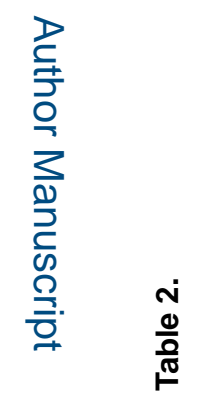

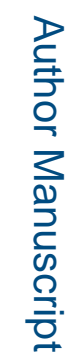

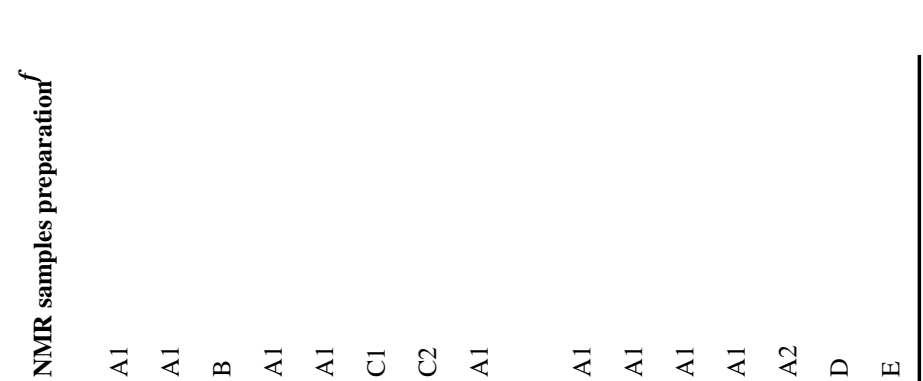

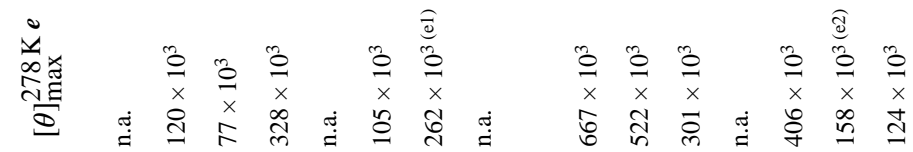

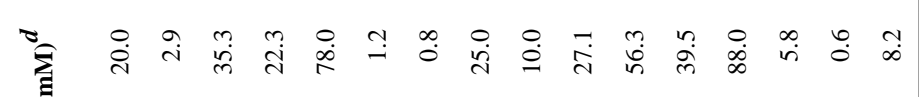

